Volume: 10 | Issue: 03| July - Sept. | 2021

EISSN: 2706-7939 ISSN: 2077-4508

DOI: 10.36632/ije/2021.10.3.12

Journal homepage: www.curresweb.com

Pages: 173-191

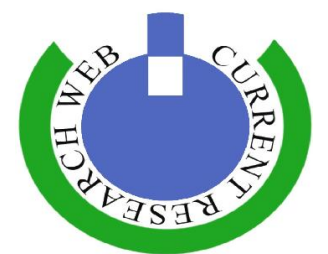

\title{
Magneto-Fluorescent Nanocomposite of Bentonite Coated Iron Oxide Nanoparticles for the Adsorption of Contaminants in Wastewater
}

\begin{abstract}
Yasser A.M. Abdulhady
Water Treatment and Desalination Unit, Hydro-geochemistry Dept., Desert Research Center, Cairo, Egypt

Received: 20 June 2021

Accepted: 15 July 2021

Published: 30 July 2021

ABSTRACT

The purpose of article is removing iron, manganese, some organic and inorganic contaminants by bentonite grafted iron oxide nanoparticles (bentonite/MIONP). Bentonite/MIONPs nanocomposite was prepared using co-precipitation method. The mean diameter of nanocomposite was $27.50 \mathrm{~nm}$. The removal efficiency of $\mathrm{Fe} \& \mathrm{Mn}$ were $89.95 \%$ and $78.82 \%$ resp. and total nitrogen \& total phosphorous were $84.65 \%$ and $84.40 \%$ resp. The reduction $\%$ of COD/BOD and TOC were $80.74 \%, 83.98 \%$ and $82.35 \%$ resp. Removal of pollutants was carried out at optimal conditions of nanocomposite dosage at $8 \mathrm{~g} / \mathrm{l}$; Contact time at $30 \mathrm{~min}$.; and $\mathrm{PH}$ at 7.0 .; temp. $50^{\circ} \mathrm{C}$. Adsorption data were reproduced by the Langmuir isotherm, where the $\mathrm{Mn}$ and Fe adsorption saturation capacity was determined as 72.04 and $206.61 \mathrm{mg} . \mathrm{g}^{-1}$ respectively. The average adsorption free energy change was $2.880 \mathrm{~kJ} \mathrm{~mol}^{-1}$, which indicated the occurrence of ionic exchange. The thermodynamic parameters implied that $\mathrm{Mn}$ and $\mathrm{Fe}$ adsorption was endothermic.
\end{abstract}

Keywords: Pollution; MIONPs, Clay, Heavy metals, COD, BOD \& TOC, Total Nitrogen \& Total Phosphorous.

\section{Introduction}

Nanotechnology has large interesting research band in future duo to have more applications. The life ecosystem is our inspection and we have to keep it healthy for plants, animals, aquatic life and humans. As a result of rapid industrialization, heavy metals, such as iron and manganese are being excessively used in numerous industries, such as fertilizer, pesticides, pigments and printing industries (Rajput et al., 2015; Meng et al., 2014). Several physical and chemical pathways that have been lead to reducing the concentration of heavy metals in order to avoid their harmful effects on ecosystems and humans such as sol gel, chemical precipitation, co-precipitation, ion exchange, and adsorption (Upadhyay et al., 2021; Younes et al., 2018 and Zhu et al., 2021). The adsorption capacity of an adsorbent material depends on the nature of the adsorbent (e.g. functional groups present, specific surface area, and pore size distribution). Solution conditions (e.g. $\mathrm{pH}$, temperature and adsorbate concentration, presence of competitive solutes, the polarity of solvent) (Duman and Ayranci, 2006). Although numerous natural and synthetic adsorbents have been reported for wastewater treatment (Hashim et al., 2011; Hasanpour, 2020). Purified bentonite are entered in several applications such as adsorbents of different pollutants (Betega et al., 2008; He et al., 2010). Heavy metal ions have a vital role in water pollution where, non-biodegradable and highly toxic. Heavy metal ions are found in different sources such as mining industries and power generation industries (Helena et al., 2011). To prevent the toxic effects of it on human health \& other animals. It should be removed from the effluents. Different methods such as adsorption, ion exchange, membrane filtration, chemical precipitation and electrochemical treatment are used for the removal of contaminants including heavy and toxic metal ions from the wastewater (Petcharoen and Sirivat 2012; Li et al., 2015). Adsorptions of heavy metals from aqueous solutions have been examined using different adsorbents (Gusain et al., 2014; Karapinar

Corresponding Author: Yasser A.M. Abdulhady, Water Treatment and Desalination Unit, Hydro-geochemistry Dept., Desert Research Center, Cairo, Egypt.

E-mail: yasser_vip6@hotmail.com, http://orcid.org/0000-0002-7816-4190 
and Donat 2009). Some organic structures form complexes with interlayer cations. Hydrogen bonds, co-ordination bonds, acid base reactions, and van der Waals forces In the case of bentonite the adsorption occurred on chemical reaction in clay actions. Varies synthesized methods such as coprecipitation (Ooi et al., 2015), hydrothermal (Abbas et al., 2013), thermal decomposition (Wang et al., 2015), microemulsion (Solano et al., 2012), electrochemical deposition (Strobel et al., 2007), laser pyrolysis (Murray, 2006), solvothermal methods (Karnland et al., 2006), sonochemical methods (Catalano et al.,2017), chemical vapor deposition (de Mello et al., 2019), the microwave assisted method (Kurlyandskaya et al., 2017), and aerosol pyrolysis (Safronov et al., 2018) have been reported to prepare the magnetic IONPs. Chemical oxygen demand measure the total quantity of oxygen required to oxidize all organic material into carbon dioxide and water. COD values are always greater than BOD values. Clay is considered as low-cost adsorbent. Clay has gained great attention in heavy metals sorption from polluted water as a result of their acceptability and applicability (Zuzana and Michaela 2015). Synthesis of clay minerals have varies silicates and aluminates groups that have active sites contain hydroxyl groups. Substitution reactions occurred by displaced $\mathrm{H}_{2} \mathrm{O}$ molecules in the interlayer space of clay by polar molecules. Bentonite has two four-dimensional layers (and one eight-dimensional layer. Moreover, nanocomposite bentonite/MIONPs have been used as a water purification agent due to their highly magnetism behaviors, high surface area, simple s methodology, non-toxicity, and proper bioavailability (Wisotzki et al., 2016; Lu et al., 2012). In addition, magnetic nanoparticles obtain on varies groups such as hydroxyl and acid groups. Therefore, these matters would have various applications for the link of compounds in water and wastewater industry. And also need to check the clay properties. Fractionation by sedimentation after removal of carbonates, organic materials, oxides and hydroxides is the first step for purification. The main treatment method is decomposition of carbonates, dissolution of iron oxides, hydroxides and silica and the oxidation of organic materials (Brazel, 2009). One of the necessary modifications is acidification that consists of a treatment of mineral with inorganic acid solution. The main target of acid activation is dissolving undesirable matters to increase specific surface area, porosity and surface acidity (Melichova and Hromada, 2012). Surface area of the alumino silicate minerals with magnetic nanoparticles had a new nanocomposite, which used for the environmental purposes as adsorbents of different pollutants (Jakir et al., 2014; Roul et al., 2013). This paper focus on surface properties of nanocomposite synthetized by magnetic modification of natural local clay and their application. Interaction between IONPs into the environment with air, water and soil make improving of surface features. As a result of this phenomena, occur changing in charging of nanomaterials (Ahmad et al., 2011). The nanoparticles ranges between 1-100 nm. MIONPs is one of the vital magnetic structure that has excellent biocompatibility character and superparamagnetic type in nano-sized diameters (Sangeetha et al., 2015). Magnetic moment and the anisotropy of nano- $\mathrm{Fe}_{\mathrm{x}} \mathrm{O}_{\mathrm{y}}$ is responsible to attach with different polluted cations (Binh et al., 1998) and also, magnetite has an ability to deal with energy of external magnetic field into thermal or mechanical response. It used in medical application such as magnetic hyperthermia (Varanda et al., 2002). Addition of materials to prevent to get excellent effeminacy (Landeloutin, 1987). Several polymers were added which have biodegradable and biocompatibility features (Vasugi and Girija 2015). A vital features of bentonite, is its large capability to absorb cations. The major constituent of bentonites was montmorillonite. The Van der Waals forces are found on these layers to attach them together. Water can enter to layers and cations to make ionic balance (Ding et al., 2009). Several researches were done by bentonite clay as adsorbent. The novality of the choice is the use of Egyptian bentonite characterized by different composition and new methodology for clay treatment.

The main focus of article is synthesis of new nanocomposite of bentonite/MIONPs. Wastewater treatment by adsorption technology and removal of iron and manganese ions $\&$ total nitrogen $\&$ total phosphorous with organic pollutants such as COD/BOD and TOC.

\section{Experimental}

\subsection{Materials}

Ferrous Sulphate six-hydrate $\left(\mathrm{FeSO}_{4} \cdot 6 \mathrm{H}_{2} \mathrm{O}\right)$ and ammonium hydroxide \& $\mathrm{NaOH} \& \mathrm{HCl}$ and nitric acid and ethyl alcohol \& Oleic acid and glacial acetic acid purchased from Merck. Natural clay was obtained from local supplier. Samples was collected from Municipal plant with sterilized bottles covered with ice cubes and kept at $4{ }^{\circ} \mathrm{C}$ for analyzing the various parameters. 


\subsection{Clay pre-treatment with inorganic acidification}

In this study, Preparation of pre-treatment Bentonite to get on pure bentonite was used as adsorbent. The samples of bentonite were dried on air at room temperature and sieved to obtain on homogenous particles. The X-Ray Fluorescence (XRF) was performed to investigate samples. The chemical content are found in Table 1 . The purification of local clay by acidification method. In our study, add to $30 \mathrm{gm}$ of raw clay several $\mathrm{HCl}$ concentration to remove inorganic compounds such some oxides and hydroxyls compounds. The second method is synthetized nano iron oxide through merging of ferrous and ferric inorganic salts prior to the reaction with $\mathrm{NH}_{4} \mathrm{OH}$ and its amount was adjusted to obtain on nanocomposite bentonite/MIONPs Alkai concentrated add to solution to get new nanocomposite (Hong et al., 2006; Bourlinos et al., 2000).

\subsection{Methodology of bentonite/MIONPs}

Synthesis of modified silicates compounds is developed by Bourlinos et al. (2000). $30 \mathrm{gm}$ of bentonite was dispersed in $400 \mathrm{ml}$ of distilled water, $150 \mathrm{ml}$ of $0.02 \mathrm{M} \mathrm{FeSO}_{4} \cdot 6 \mathrm{H}_{2} \mathrm{O}$ and pH adjusted to 3.5 by citric acid was added dropwise under stirring. After stirring for $30 \mathrm{~min}$. addition of $\mathrm{NH}_{4} \mathrm{OH}$ with drop wise of $\mathrm{NaOH}$ to get on precipitation of IONPs. The suspension was centrifuged and washed more times with water. The wet residue was dried in air. The mixture was added to excess glacial acetic acid for $1 \mathrm{~h}$ at $60{ }^{\circ} \mathrm{C}$, crushed into powder and calcined in air at $450{ }^{\circ} \mathrm{C}$ for $2 \mathrm{~h}$ to get the new nanocomposite bentonite/MIONPs (Mahdavi et al., 2007; Tsukasa, 2017). The role of surfactants join to the surface of the nano-formed and increase a steric hindrance to aggregation. Then on solution (Nasser et al., 2018).

\subsection{Instrument Investigation of nanocomposite bentonite/MIONPs}

The XRD pattern of nanocomposite bentonite/MIONPs was obtained using a X-ray diffractometer Schimadzu model: A PAN analytical X-rays diffraction equipment model Expert PRO with secondary mono-chromator, Cu-radiation $\left(\lambda=1.54 \mathrm{~A}^{0}\right)$ at $50 \mathrm{k} . \mathrm{V} ., 40$ M.A and scanning speed $0.02^{\circ}$ /sec. saturation magnetization of nanocomposite estimated by a vibrating-sample magnetometer (VSM, Homade 2tesla). A magnet $(\Phi 17.5 \times 20 \mathrm{~mm}, 5500 \mathrm{O}$ e) was utilized for the collection of magnetic particles. Coercivity, remanence and saturation of samples have been estimated. FT-IR spectroscopy were measured in a transmission mode on a spectrophotometer (PerkinElmer Spectrum Version 10.03.09) Spectrum Two Detector $\mathrm{LiTaO}_{3}$ was used for separating the solid and liquid during the preparation samples. The samples were pressed pellets of a mixture of the powder with KBr. The micrographs of nanocomposite were obtained using SEM Model Quanta 250 FEG (Field Emission Gun). A plasma-atomic emission spectrometer (ICP-AMS, Optima 3000XL, Perkin Elmer) used for detecting the concentrations of trace metal ions. Chemical Oxygen Demand is a measure of the biologically content and inert organic matter that is susceptible to oxidation by a strong oxidizing agent. Method depends on closed dichromate-reflux colorimetric method. Adding to the reagent vial, digested under closed reflux conditions, and allowed to cool before measurement is taken. COD is used to evaluate contaminants to determine the efficiency of treatment processes. In general, the formation of magnetic iron nano-particles followed this reaction.

$$
\mathrm{Fe}^{2+}+2 \mathrm{Fe}^{3+}+8 \mathrm{NH}_{3} \cdot \mathrm{H}_{2} \mathrm{O} \longrightarrow \mathrm{Fe}_{3} \mathrm{O}_{4} \downarrow+8 \mathrm{NH}_{2}+4 \mathrm{H}_{2} \mathrm{O}
$$

Noteworthy to mention that when ammonia is added to the $\mathrm{FeCl}_{2}$ and $\mathrm{FeCl}_{3}$ solutions, $\mathrm{Fe}(\mathrm{OH})_{2}$ is initially formed (Eq. 1), which is then oxidized to $\mathrm{Fe}_{3} \mathrm{O}_{4}$ (Eq. 2). The formation mechanisms of $\mathrm{Fe}_{3} \mathrm{O}_{4}$ magnetic NPs can be summarized as follows:

$\mathrm{Fe}^{2+}+2 \mathrm{NH}_{3}+\mathrm{H}_{2} \mathrm{O} \rightarrow \mathrm{Fe}(\mathrm{OH})_{2}+2 \mathrm{NH}_{4}^{+}$

$3 \mathrm{Fe}(\mathrm{OH})_{2}+1 / 2 \mathrm{O}_{2} \rightarrow \mathrm{Fe}_{3} \mathrm{O}_{4}+3 \mathrm{H}_{2} \mathrm{O}$.

\subsection{Equation of removal efficiency on wastewater contaminants Adsorption percentage was calculated using the following equation.}

$\%$ Removal $=(\mathrm{Ci}-\mathrm{Cf}) / \mathrm{Ci} * 100$. 
In this equation $\mathrm{Cf}$ and $\mathrm{Ci}$ are the initial and final concentration of heavy metals in solution, respectively. Then the following equation was used to determine the adsorption capacity:

$\mathrm{Q}_{\mathrm{e}}=\left(\mathrm{C}_{0}-\mathrm{C}_{\mathrm{e}}\right) \mathrm{V} / \mathrm{M}$

In this equation, qe is adsorption capacity and $\mathrm{C} 0$ and $\mathrm{Ce}$ are initial and balanced concentration of heavy metals in liquid phase ( $\mathrm{mg} / \mathrm{l})$. V is volume of the solution (L) and $\mathrm{M}$ is the amount of used adsorption (g).

\subsection{Procedure experiment of Total Nitrogen (TN)}

Total Kejeldahl Nitrogen (TKN), Ammonia $\left(\mathrm{NH}_{3}{ }^{+}\right)$, Nitrite $\left(\mathrm{NO}_{2}^{-}\right)$and Nitrate $\left(\mathrm{NO}_{3}{ }^{-2}\right)$.

Total Nitrogen $(\mathrm{TN})=\mathrm{R}-\mathrm{N}($ Organic Nitrogen $)+\mathrm{NH}_{3}++\mathrm{NO}_{2}{ }^{-}+\mathrm{NO}_{3}{ }^{-2}$.

All components that comprise Total nitrogen are biochemically interconvertible, are components of the nitrogen cycle, and can occur in both wastewater and natural waters (Standard Methods) (Ahmadreza et al., 2015). Transfer $50 \mathrm{~mL}$ of sample $50 \mathrm{~mL}$ into a $125 \mathrm{ml}$ flask and add $1 \mathrm{~m}$ of $11 \mathrm{~N}$ sulfuric acid. Then, Add $0.4 \mathrm{~g}$ ammonium persulfate, mix and boil for approximately 30-40 minutes. Then heat for 30 minutes in an autoclave at $121^{\circ} \mathrm{C}$. Cool and dilute to $40 \mathrm{ml}$ and filter. For each sample analyzed, including quality control samples, record the volume filtered and oven dry mass in the appropriate places. Calculate TSS using equation.

\subsection{Isotherm studies}

In general, adsorption isotherm models are explained to detect the maximum uptake capacity of an adsorbent and to identify the adsorption mechanism. The experimental part of this study was performed by shaking, for $30 \mathrm{~min}$ at room temperature and in a thermostatic water bath shaker, $15.0 \mathrm{mg}$ of the prepared magnetic nanocomposite with several $100 \mathrm{ml}$ pollutant ions aliquots of different concentrations; ranged from 25 to $200 \mathrm{mg} / \mathrm{L}$. The $\mathrm{pH}$ of all solutions was adjusted to 7.0. After shaking, magnetic nanocomposite was separated and the remaining concentration of $\mathrm{Fe}$ and $\mathrm{Mn}$ ions was determined by the aforementioned method. Langmuir and Freundlich isotherm, were examined to analyze the collected data. Langmuir model assumes monolayer adsorption of the adsorbate at homogeneous binding sites on the adsorbent surface (Guibal et al., 1998). Freundlich model supposes multi-layer adsorption of the adsorbate on the heterogeneous surface of the adsorbent (Freundlich, 1906).

\subsection{Kinetic studies}

Kinetic models were examined to see which evaluate the current adsorption process. The experimental part of this study was performed as follows: at room temperature and in a thermostatic water bath shaker, $15.0 \mathrm{mg}$ of magnetic nanocomposite was shaken, separately, with different concentration of $\mathrm{Fe}$ and $\mathrm{Mn}$ ions solution for different time intervals. The $\mathrm{pH}$ of all solutions was adjusted to 7.0. After shaking, magnetic nanocomposite was separated and the remaining concentration of Fe and Mn ions was determined by the aforementioned method.

\subsection{Thermodynamic studies}

The thermodynamic nature of an adsorption process is generally deduced from the numerical values of three thermodynamic parameters, Gibbs free energy $\left(\Delta \mathrm{G}^{\circ}\right)$, standard entropy change $\left(\Delta \mathrm{S}^{\circ}\right)$ and standard enthalpy change $\left(\Delta \mathrm{H}^{\circ}\right)$. Mathematically, these parameters are calculated from equations listed in Table 11. Data required for the thermodynamic study were collected by shaking $15.0 \mathrm{mg}$ of the adsorbent with $100 \mathrm{~mL}$ solution at different temperatures (from 303 to $323 \mathrm{~K}$ ) for $30 \mathrm{~min}$. The amount of $\mathrm{Fe}$ and $\mathrm{Mn}$ ions in the filtrate was detected by the aforementioned procedure. 


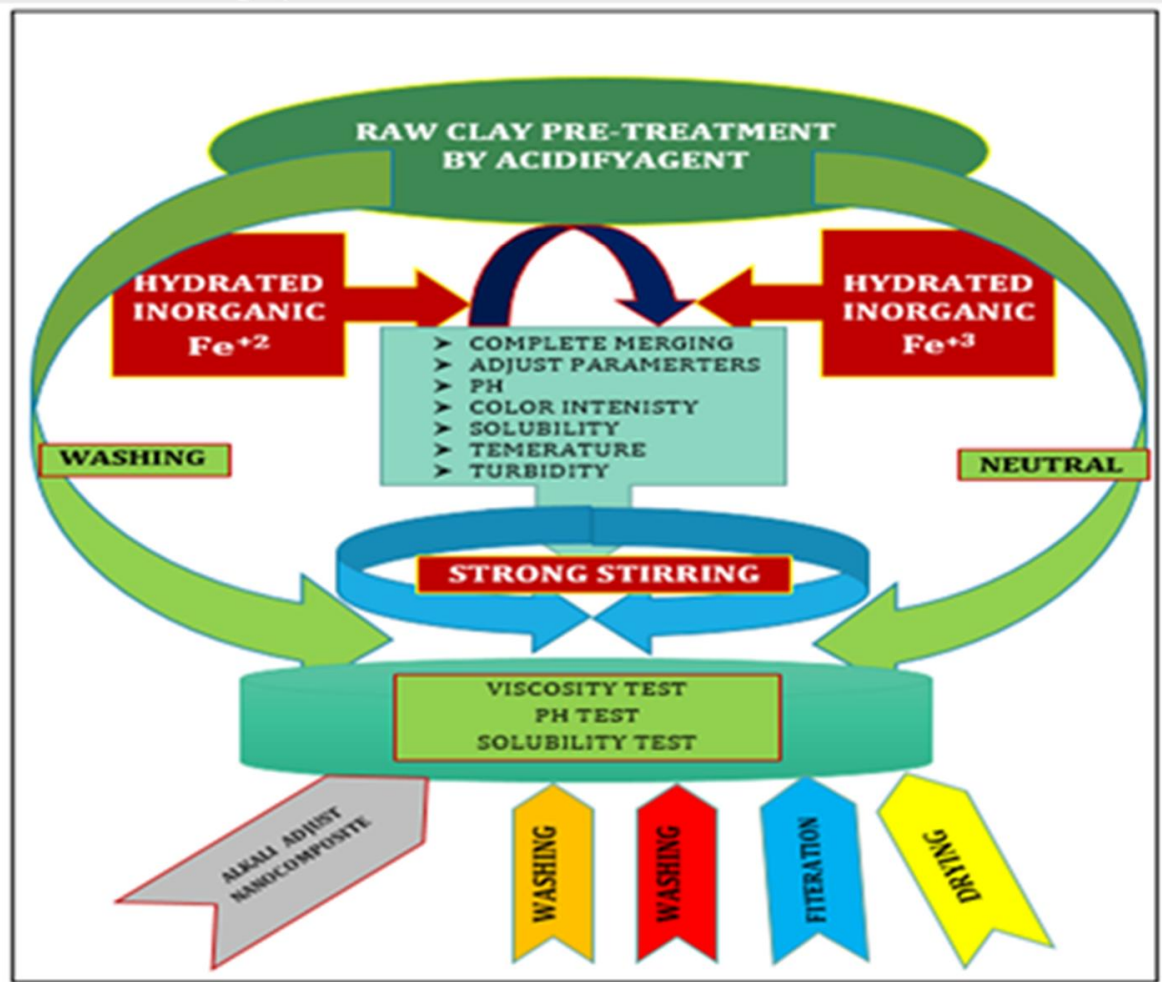

Fig. 1: Schematic of methodology of bentonite/MIONPs

\section{Results and Discussion}

\subsection{Chemical composition of metal oxides of bentonite clay}

Table. 1 Showed the chemical composition of different oxide and compounds that attached with each other's by tetragonal and octagonal structures as in bentonite. The poly-silicates and polyaluminates compound as shown in (table 1) showed as a core of varies structures. Different crystallographic shapes of bentonite was help in increase the surface area. Acidification methodology for clay mineral treatment was more suitable for local Egyptian specifications (table.1).

Table 1: Chemical analysis of bentonite clay by XRF

\begin{tabular}{lllllllll}
\hline Composition \% & $\mathrm{SiO}_{2}$ & $\mathrm{Al}_{2} \mathrm{O}_{3}$ & $\mathrm{Fe}_{2} \mathrm{O}_{3}$ & $\mathbf{C a O}$ & $\mathbf{M g O}$ & $\mathrm{K}_{2} \mathrm{O}$ & $\mathrm{Na}_{2} \mathrm{O}$ & Others \\
\hline Natural clay & 61.04 & 23.87 & 5.32 & 3.64 & 2.92 & 1.10 & 1.45 & 0.66 \\
Treated clay & 53.20 & 16.19 & 17.14 & 0.39 & 0.71 & 1.80 & 0.67 & 9.90 \\
\hline
\end{tabular}

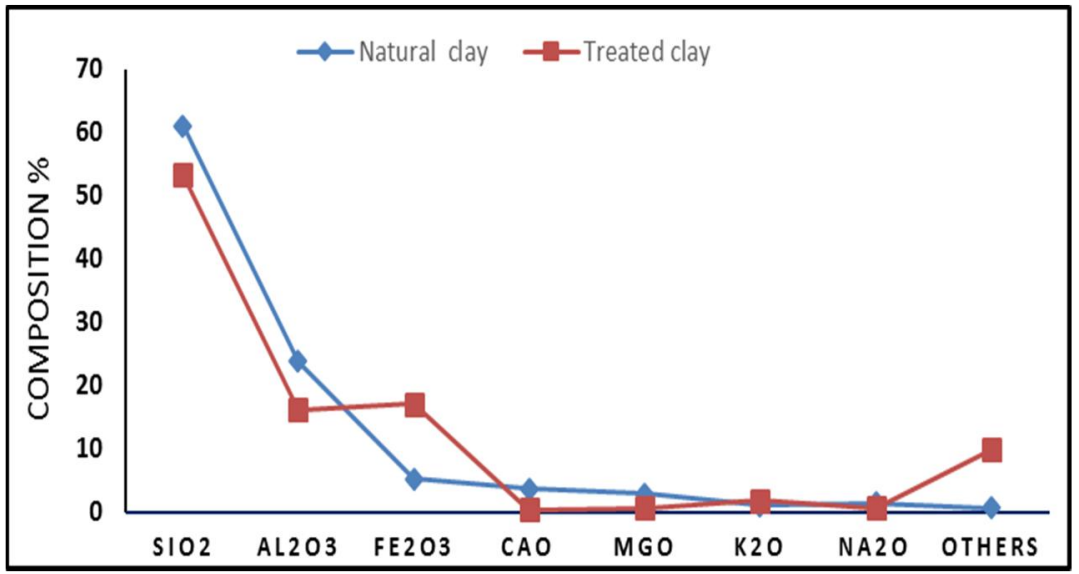

Fig. 2: Chemical composition of bentonite before and after acidified purification by x-ray fluorescence 
The chemical treatment of clay in this article depends on solubilsation of different materials in acidic medium to gotten on matrix that excellent used as supported material in wastewater treatment with high mechanical strength. Bentonite had different structure in tetragonal and octagonal shapes. The X-ray fluorescence analysis showed silicates and aluminates as core constituent of natural bentonite. In bentonite structure found $\mathrm{Si}-\mathrm{O}$ and $\mathrm{Al}-\mathrm{O}$ bonds, these bonds contain active sites on oxygen atoms and hydroxyl groups. The bentonite clay had a definite structure which depends on varies crystallographic shapes.

\subsection{Characterization of the bentonite/MIONPs}

\subsubsection{Assessment of $x$-ray diffraction analysis}

Figure. 3 showed that different sharp peaks intensity at 2 theta $22.50,32.50,44.50,46.50,53.50$, 59.50. The band can be apportioned to the partially crystalline nature of bentonite complex molecules. The broad band's had less 2 theta values than 30 , it has confirmed to bentonite and different mineral in clay. The positions and relative intensities of the reflection peak of $\mathrm{Fe}_{3} \mathrm{O}_{4}$ and $\mathrm{Fe}_{2} \mathrm{O}_{3}$ agree with the XRD diffraction peaks of iron oxide nanoparticles. The peak of MIONPs appeared on 32.50, 44.50 and 46.50 according to standard peak intensity of iron nanoparticles. Broad peaks showed at, 44.50 related to magnetite in nano-sized and appear peaks on 2 theta 32.50 for hematite particles which contained by oxidation of magnetite. At 2 theta peak intensity at 59.50 form a new nanocomposite of bentonite/MIONPs. Appearing of this peak indicate that nanocomposite formation prepared with high performance and new crystallographic figure formed (Cornell and Schwertmann 2003, Sarma 2014)
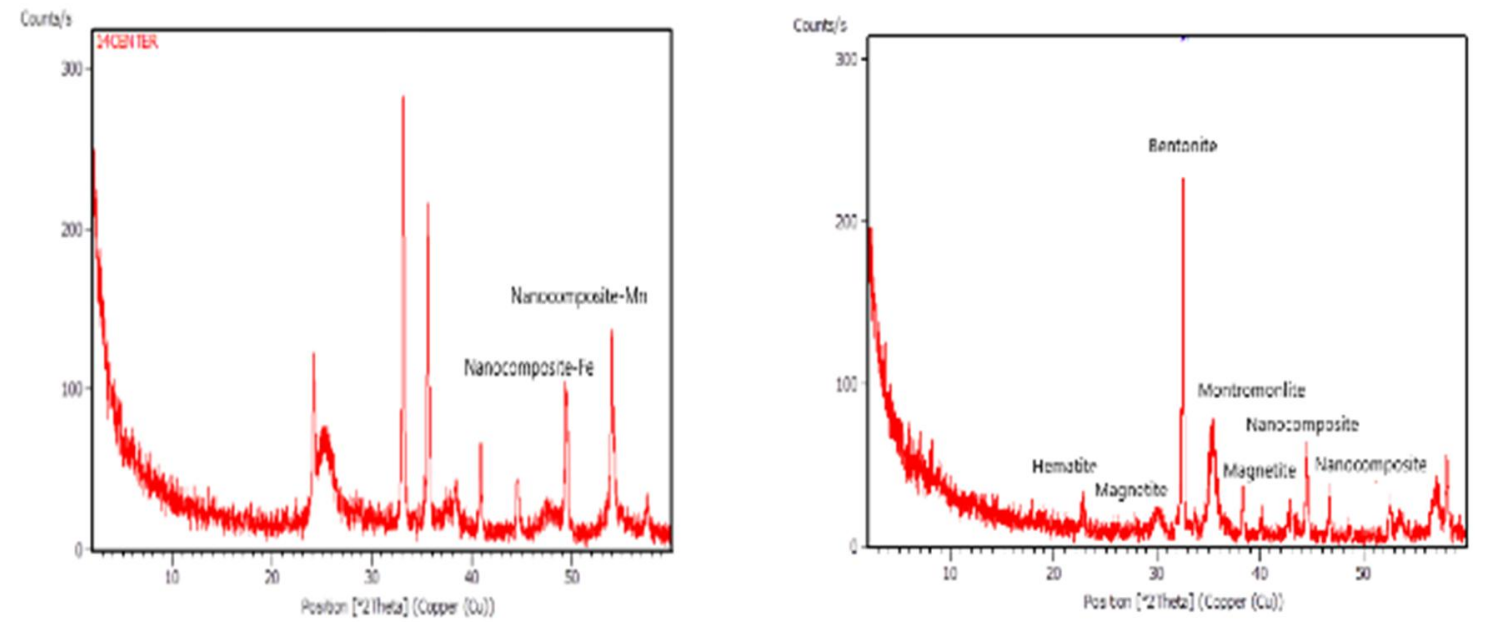

Fig. 3: XRD figure of bentonite/MIONPs before and after treatment

\subsubsection{Scanning electron microscope (SEM) of bentonite/MIONPs}

Fig. 4 illustrated to the surface area of nanocomposite bentonite/MIONPs. Fig. 4 confirmed the cubic and spherical shape of nanocomposite bentonite/MIONPs coated in bending shapes. The SEM showed an effective inorganic salts of iron to consist of nano-pellets with different shapes. By using mixing of iron nano-formed donated the spherical of nanoparticles with large surface area. Photo $\mathrm{C}$ and D showed the big surface area of nanocomposite bentonite/MIONPs. The synthesized nanocomposite had more active sites that had several functional groups the improvement surface modification (Elı'as et al., 2010). 

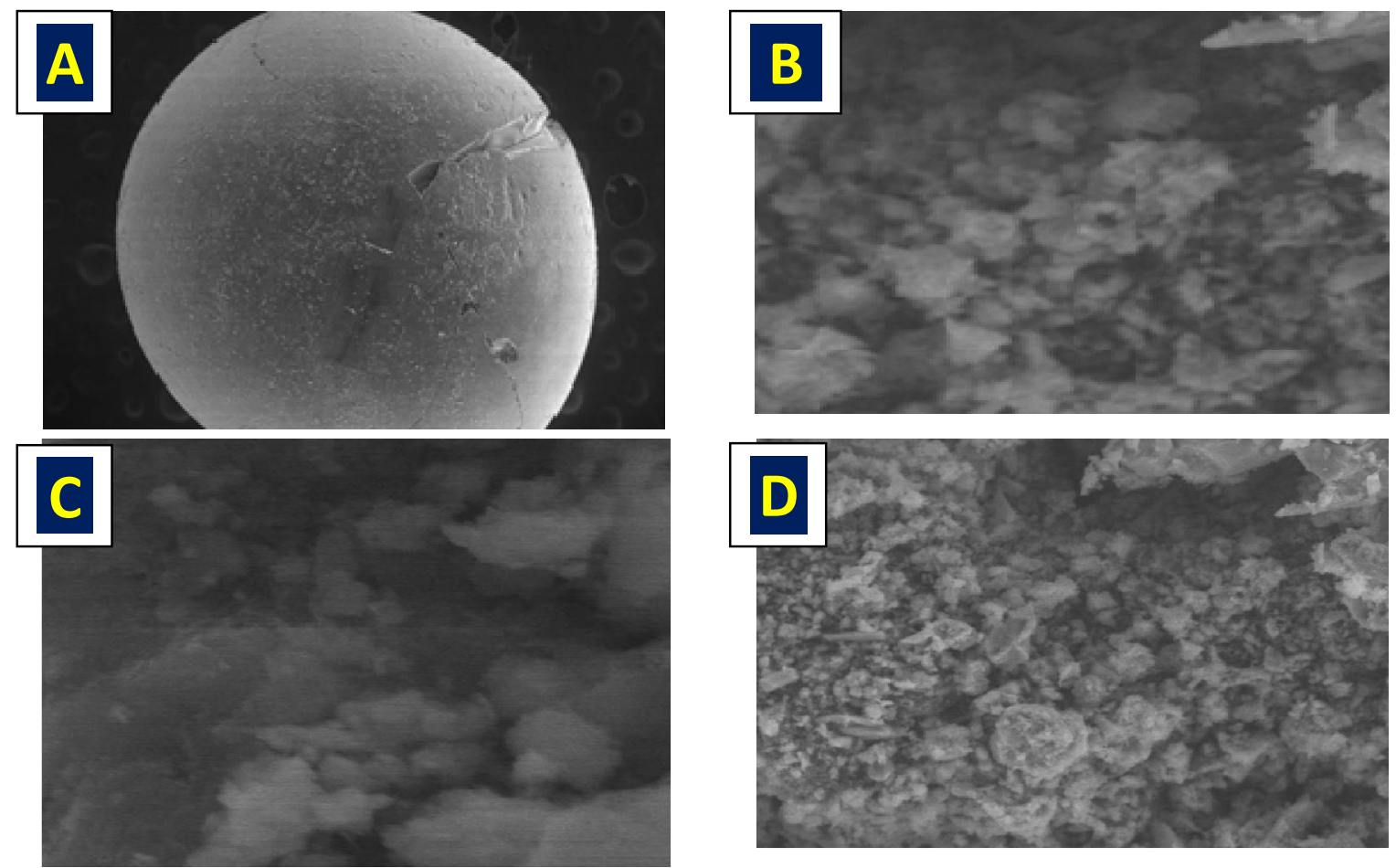

Fig. 4: Scanning Electron microscopeshow the surface sites of bentonite/MIONPs

\subsubsection{FT-IR spectroscopy of bentonite/MIONPs}

Figure. 5 transmission peaks at $507 \mathrm{~cm}^{-1}$ and $470 \mathrm{~cm}^{-1}$ showed the $\mathrm{Fe}-\mathrm{O}$ vibration related to the iron oxide nanoparticles. Two peaks of transmission peaks at 2,215 and 2,234 cm-1 were attributed to the asymmetric $\mathrm{C}-\mathrm{H}$ stretching and the symmetric $\mathrm{C}-\mathrm{H}$ stretching, respectively. The aliphatic $\mathrm{C}-\mathrm{H}$ stretching, in $1411 \mathrm{~cm}^{-1}$ were because of $\mathrm{C}-\mathrm{H}$ bending vibrations (Tamas et al., 2007). The broad band at $631-608 \mathrm{~cm}-1$ is likely due to the vibration of the $\mathrm{Si}-\mathrm{O}$ bonds. The IR band at $3020 \mathrm{~cm}^{-1}$ can be showed to the stretching modes of surface $\mathrm{H}_{2} \mathrm{O}$ molecules. Two transmission bands position between 660 and $1000 \mathrm{~cm}^{-1}$ contribute to the bending of silica linkages and vibration of silica-alumina linkages, were detected; a transmission peak at wavelength $1411 \mathrm{~cm}^{-1}$ attributed to the stretching of silica can also be detected. The intensities of the abovementioned peaks varied from one structure to another. A variation of intensity in transmission bands indicated to associate differences between the compared structures. The main IR bands were as follows: $1100-1000 \mathrm{~cm}^{-1}$ related to Si-O and asymmetrical stretch $1100 \mathrm{~cm}^{-1}$ showed to Al-O. Symmetrical stretch $\left(502-531 \mathrm{~cm}^{-1}\right)$ bend to Si-O-Al. (459 - 470 $\mathrm{cm}^{-1}$ ) double ring vibrations related to the interaction between (Si-O-Al). Sharp peak appears at 873 $\mathrm{cm}^{-1}$ indicate to new linkage asymmetrical stretching band of Si-O-Fe/Al-O-Fe. The idea of strictly separated external and internal tetrahedral vibrations must be modified in that bentonite framework vibrations appear to be strongly coupled. Hydroxyl groups connected to clay structures are most vital for understanding chemistry of adsorption mechanism (Danková et al., 2017). IR spectroscopy is a major characterization test of adsorbate systems and gave us the prediction of new compounds forms. The peaks at some (558 to $652-538 \mathrm{~cm}^{-1}$ ) that is showed to the (nanocomposite Fe-O and Mn-O) bond after treatment (Habib et al., 2018).

\begin{tabular}{ccll}
\hline $\begin{array}{l}\text { Nanocomposite bentonite/MIONPs } \\
\text { Before treatment }\left(\mathbf{c m}^{-1}\right)\end{array}$ & $\begin{array}{l}\text { Nanocomposite bentonite/MIONPs } \\
\text { After treatment }(\mathbf{F e} / \mathbf{M n})\left(\mathbf{c m}^{-1}\right)\end{array}$ \\
\hline Fe-O & $470-507$ & Nano comp. -O-Fe & $562-558$ \\
C-H & $2,215-2,234$ & Nano comp. -O-Mn & 538 \\
Si-O & $631-608$ & & \\
Al-O & 1100 & & \\
Si-O-Al & $502-531$ & & \\
Si-O-Fe & 873 & & \\
Al-O-Fe & 873 & & \\
\hline
\end{tabular}



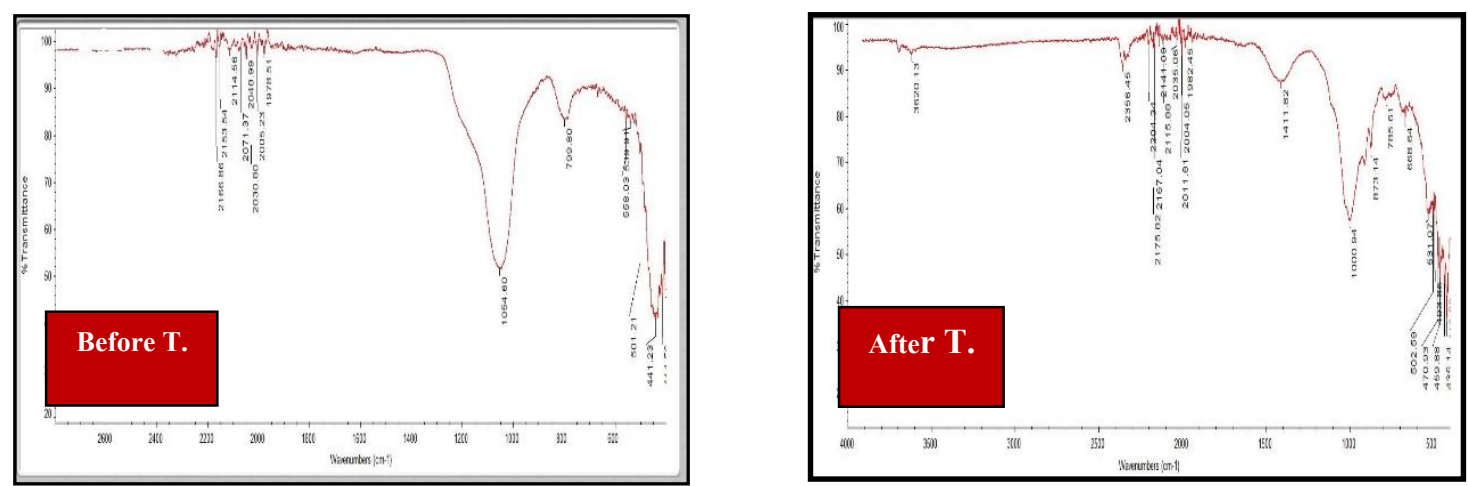

Fig. 5: IR-Spectroscopy of nanocomposite bentonite/MIONPs before \& after treatment

\subsubsection{Magnetic characterization of nanocomposite bentonite/MIONPs}

Fig. 6 showed that Vibrating sample magnetometer (VSM) discussed on a magnetic characterization of prepared nanocomposite. The low hysteresis value in the magnetization chart explained that nanocomposite had some paramagnetic strength that may be increase the capability attraction between nanocomposite and different pollutants (Indira et al., 2010). The magnetization saturation (MS) values of MIONPs, bentonite and bentonite/MIONPs was $46.8701 \mathrm{emu} / \mathrm{g}, 12.8488$ $\mathrm{emu} / \mathrm{g}, 3.46329 \mathrm{emu} / \mathrm{g}$ respectively. Fig. 7 showed that MIONPs had a highest value of MS than others. The reading value of MS bentonite has small result. (World Health Organization, 2004).

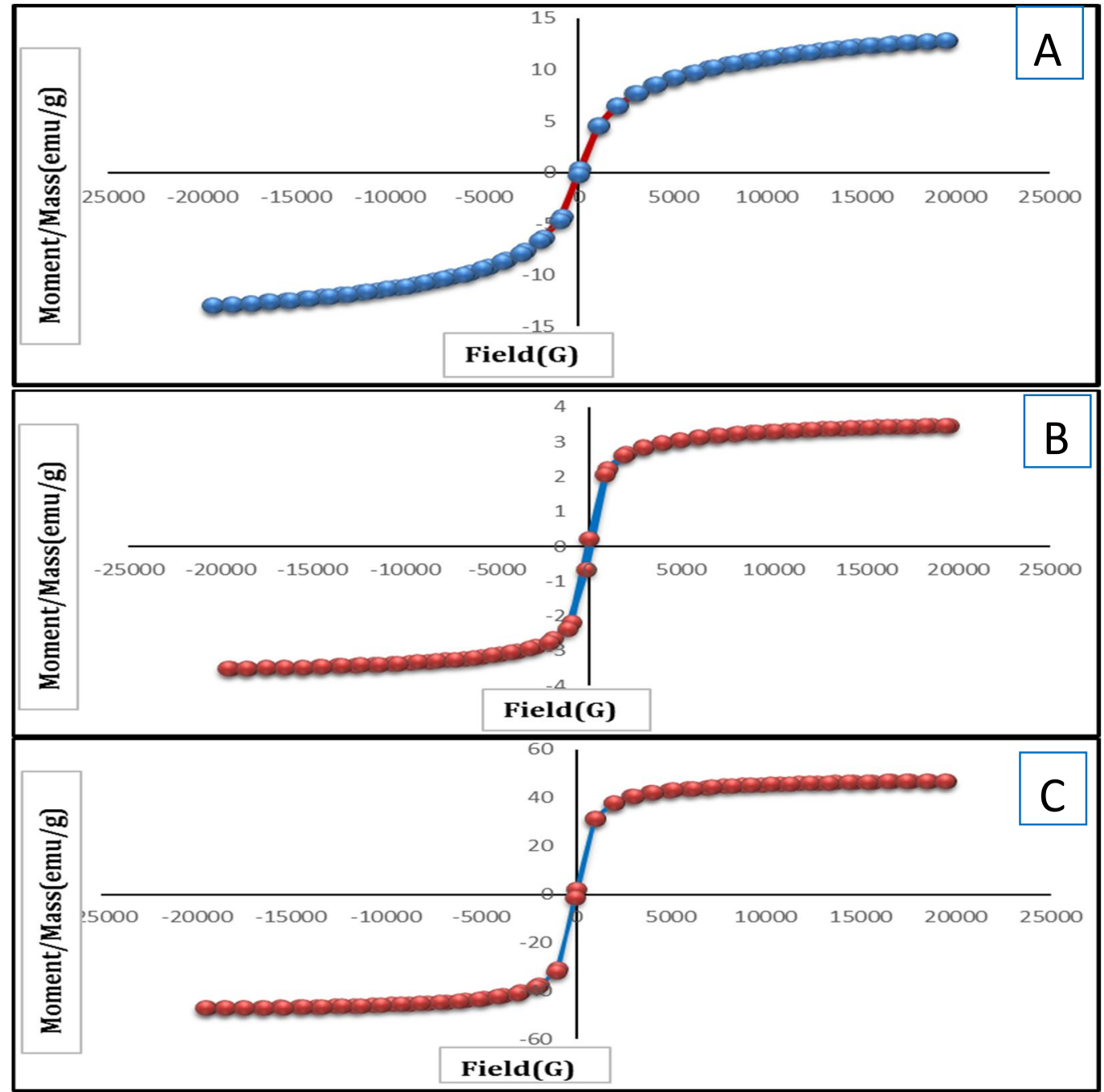

Fig. 6: VSM charts of A. nanocomposite bentonite MIONPs; B. MIONPs; C. bentonite 


\subsubsection{Particle size analysis of nanocomposite bentonite/MIONPs}

Fig. 7 showed that the mean particle size and morphology of nanocomposite bentonite MIONPs is nearly spherical and crystalline in shape. The nanoparticles intensity weighting was $55.50 \mathrm{~nm}$, volume weighting was $18.50 \mathrm{~nm}$ and number weighting was $9.50 \mathrm{~nm}$. The mean diameter of nanocomposite material ranges around $27.80 \mathrm{~nm}$. This reading data meant that reduction $\%$ of bentonite/MIONPs depends on the size and shape with availability of dispersion \%. The particle size distribution test showed the distribution of nano-sized particles in solution and dispersity efficiency to remove pollutants by adsorption process.

Table 2: VSM measurements values for nanocomposite bentonite/MIONPs

\begin{tabular}{lccc}
\hline Parameters & MIONPs (C) & Bentonite (A) & bentonite/MIONPs(B) \\
\hline Coercivity (Hci) & $250.41 \mathrm{G}$ & $569.21 \mathrm{G}$ & $623.80 \mathrm{G}$ \\
Magnetization (Ms) & $46.8701 \mathrm{emu} / \mathrm{g}$ & $12.8488 \mathrm{emu} / \mathrm{g}$ & $3.46329 \mathrm{emu} / \mathrm{g}$ \\
Retentivity (Mr) & $7.8590 \mathrm{emu} / \mathrm{g}$ & $1.3012 \mathrm{emu} / \mathrm{g}$ & $0.21450 \mathrm{emu} / \mathrm{g}$ \\
\hline
\end{tabular}

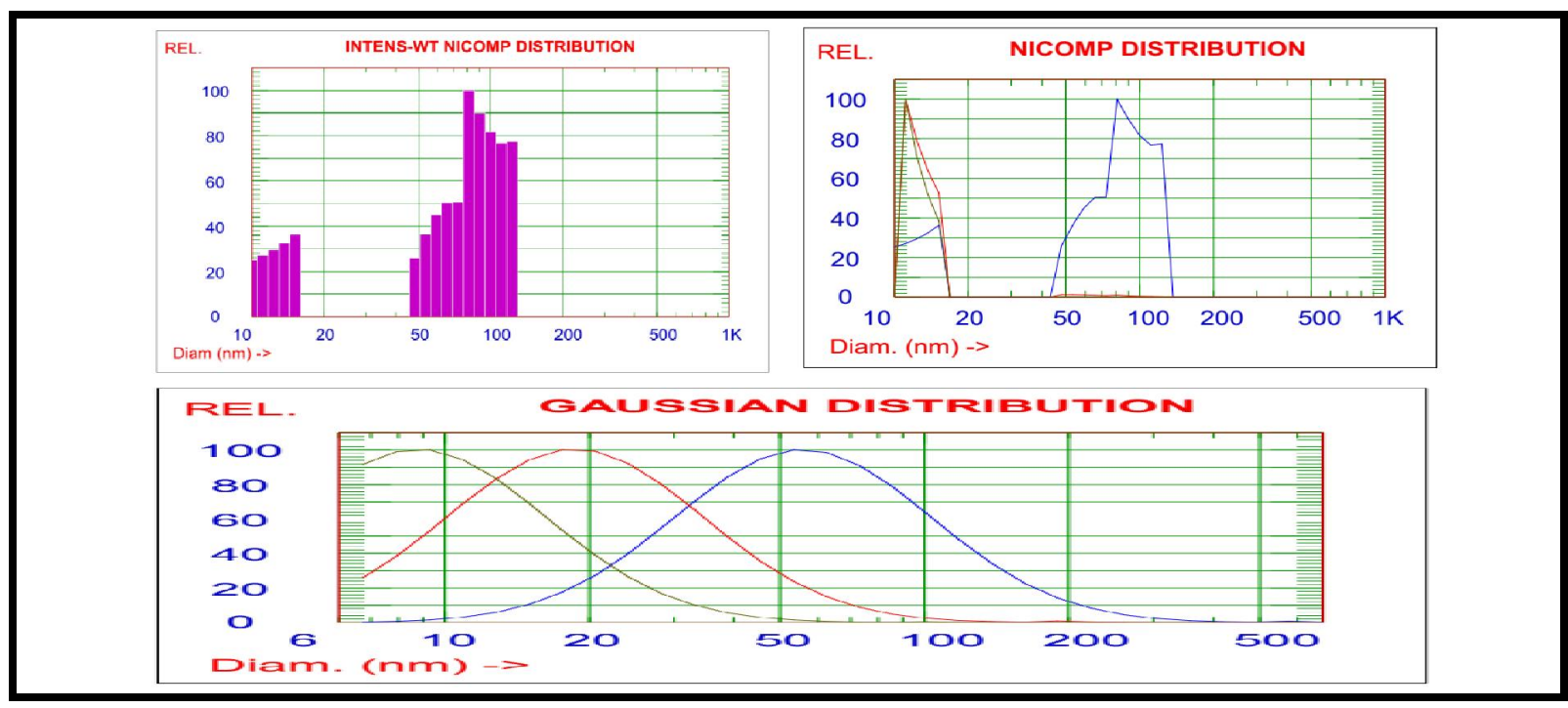

Fig. 7: Particle size distribution (Nano-sized) of nanocomposite bentonite/MIONPs

\subsection{Study effect optimal conditions of nanocomposite bentonite/MIONPs for removal wastewater heavy metals}

Table 3. Showed the optimal conditions of different parameters such as $\mathrm{pH}$, Temperature degree, contact time and nanocomposite dosage. Adsorption technology was the major responsible for removal different pollutants such as Municipal heavy metals and other pollutants. Nanocomposite of bentonite/MIONPs dosage was $8 \mathrm{~g} / \mathrm{l}$. The highest reduction \% value of reaction temperature was at 50 ${ }^{0} \mathrm{C}$ for bentonite/MIONPs, contact time was at 30 minutes and $\mathrm{pH}$ solution at 7.00.

\subsection{Effect of bentonite/MIONPs on removal of wastewater heavy metals}

Table. 4 showed the heavy metals of wastewater samples that have impermissible limit of iron and manganese. These toxic metals have chemical activities to attach with different organic and inorganic compounds. So, in this study, focused on preparation of nanocomposite bentonite/MIONPs that had a specific adsorption data. Nanocomposite bentonite/MIONPs could achieve excellent removal $\%$. Whereas, these materials had a specific surface area and also a definite crystallographic shape. Table. 4 also showed the values of heavy metals and other toxic materials.

\subsubsection{Effect of different concentrations of synthesized polluted Iron ion on reduction \% at optimal conditions of nanocomposite bentonite/MIONPs}

Table. 5 Illustrated the effect of different iron concentration on reduction percent of pollutants. The highest removal \% value of iron ions was at $40 \mathrm{ppm}$ at optimal condition of nanocomposite 
bentonite/MIONPs before. The value of reduction $\%$ after $40 \mathrm{ppm}$ iron diminished. This might be due to minimize the active site functional groups on nanocomposite bentonite/MIONPs.

Table 3: Optimal conditions of nanocomposite bentonite/MIONPs for wastewater heavy metals

\begin{tabular}{cccccc}
\hline $\mathbf{p H}$ & $\begin{array}{c}\text { Nanocomposite } \\
\text { Dose (Wt./V) }\end{array}$ & $\begin{array}{c}\text { Reduction } \\
\mathbf{\%}\end{array}$ & $\begin{array}{c}\text { Contact } \\
\text { Time (min.) }\end{array}$ & $\begin{array}{c}\text { Nanocomposite } \\
\text { Dose (Wt./V) }\end{array}$ & $\begin{array}{l}\text { Reduction } \\
\text { \% }\end{array}$ \\
\hline $\mathbf{3}$ & & 80.00 & $\mathbf{1 0}$ & & 74.01 \\
$\mathbf{5}$ & $8 \mathrm{~g} / 1$ & 84.11 & $\mathbf{3 0}$ & $8 \mathrm{~g} / 1$ & 87.23 \\
$\mathbf{7}$ & & 87.50 & $\mathbf{6 0}$ & 83.05 \\
$\mathbf{9}$ & & 79.72 & $\mathbf{9 0}$ & 82.94 \\
\hline Temp. & Nanocomposite & Reduction $\%$ & Nanocomposite Dose & Reduction $\%$ \\
${ }^{\circ} \mathrm{C}$ & Dose (Wt./V) & & (Wt./V) & 83.22 \\
\hline $\mathbf{3 0}$ & & 82.50 & $\mathbf{4}$ & 87.39 \\
$\mathbf{4 0}$ & & 85.17 & $\mathbf{6}$ & 91.07 \\
$\mathbf{5 0}$ & $8 \mathrm{~g} / 1$ & 88.45 & $\mathbf{8}$ & 84.60 \\
$\mathbf{6 0}$ & & 86.20 & $\mathbf{1 0}$ & \\
\hline
\end{tabular}
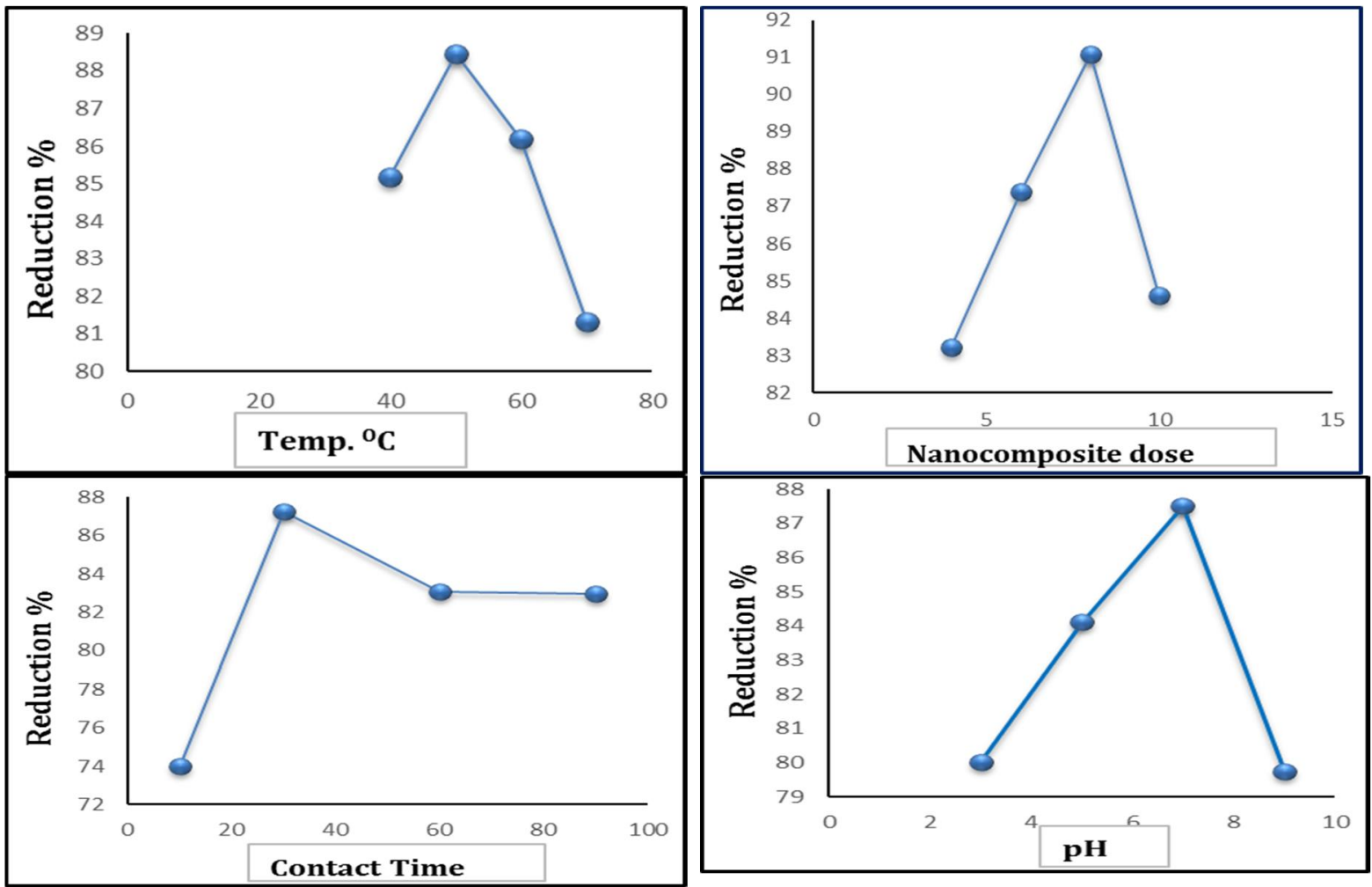

Fig. 8: Showed the optimal conditions of nanocomposite of bentonite/MIONPs

Table 4: Effect of bentonite/MIONPs on heavy metals removal

\begin{tabular}{cccccc}
\hline $\begin{array}{c}\text { Parameter } \\
\text { mg/l }\end{array}$ & $\begin{array}{c}\text { Permissible limit } \\
\text { (Magdy et al., 2015) }\end{array}$ & $\begin{array}{c}\text { Present study* } \\
\pm \text { SD }\end{array}$ & $\begin{array}{c}\text { Before } \\
\text { Treatment }\end{array}$ & $\begin{array}{c}\text { After } \\
\text { Treatment }\end{array}$ & Reduction \% \\
\hline Iron & $<0.3$ & $2.04 \pm 0.50$ & 14.235 & 2.134 & 85.00 \\
Manganese & $<0.5$ & $0.37 \pm 0.10 \mathrm{~S}$ & 06.470 & 0.612 & 90.54 \\
\hline
\end{tabular}

Optimal conditions; Nanocomposite dosage: $8 \mathrm{~g} / \mathrm{l}$; Contact time: $30 \mathrm{~min}$.; Temp.: $50{ }^{\circ} \mathrm{C}$; PH: 7.0

Table 5: Effect of different concentration of synthetized polluted Iron ion on reduction \%

\begin{tabular}{lccc}
\hline Parameter mg/l & Synthetized Soln. Conc. Before Treatment & After Treatment & Reduction \% \\
\hline \multirow{3}{*}{ Iron } & 20 & 2.04 & 89.80 \\
& 40 & 4.40 & 89.95 \\
& 80 & 8.50 & 89.37 \\
\hline
\end{tabular}

Optimal conditions; Nanocomposite dosage: $8 \mathrm{~g} / \mathrm{l}$; Contact time: 30 min.; Temp.: $50{ }^{\circ} \mathrm{C}$; $\mathrm{PH}: 7.0$ 


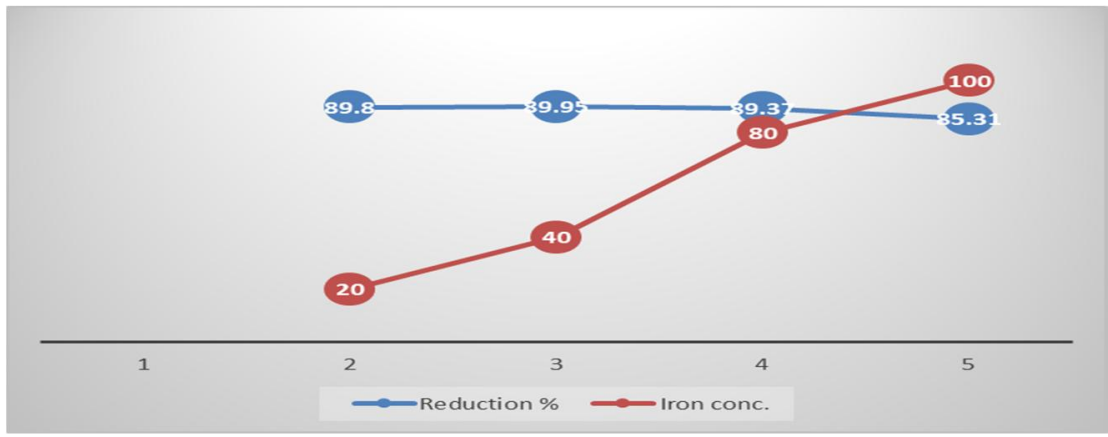

Fig. 9: Relation between toxic iron metal with reduction percent

\subsubsection{Effect of different concentrations of synthesized polluted Manganese ion on reduction \%}

Table. 6 showed the effect of Manganese ions concentration on nanocomposite bentonite/MIONPs. When the active sites of nanocomposite surface reach to supersaturation of polluted element, the reduction percent will decrease. At $50 \mathrm{ppm}$, the reduction percent of manganese was $78.82 \%$ and it was the highest value. After this value the reduction \% will decreased.

Table 6: Effect of different concentration of synthetized polluted Manganese ion on reduction $\%$

\begin{tabular}{cccc}
\hline Parameter mg/l & Synthetized Soln. Conc. Before Treatment & After Treatment & Reduction \% \\
\hline \multirow{3}{*}{ Manganese } & 10 & 2.77 & 72.30 \\
& 50 & 10.59 & 78.82 \\
& 60 & 14.73 & 75.45
\end{tabular}

Optimal conditions; Nanocomposite dosage: 8 g/l; Contact time: 30 min.; Temp.: $50{ }^{\circ} \mathrm{C}$; PH: 7.0

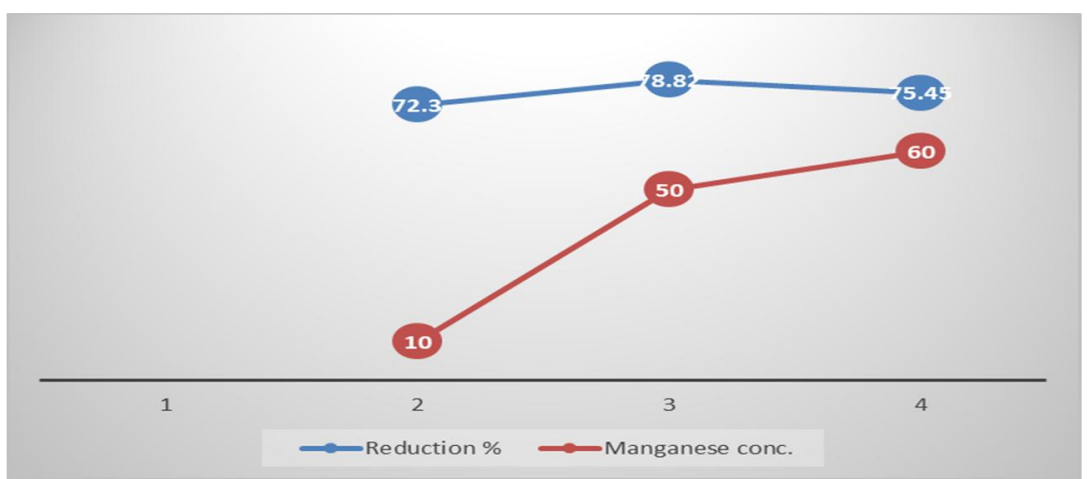

Fig. 10: Relation between toxic manganese metal with reduction percent

\subsection{Chemical treatment of total nitrogen \& total phosphorous by nanocomposite montmorillonite and zeolite/IONPs}

Table. 7 showed that the total nitrogen value in wastewater of sample before treatment was 56.87 $\mathrm{ppm}$. But after treatment, the value reduced to $10.43 \mathrm{ppm} \&$ reduction percent was $81.65 \%$. On the other hand, the lowest ammonium removals were achieved for the sample solution contained on the highest ammonium concentration. This may be due to the real that the larger ammonium ions content, had a difficult purpose because only a certain quantity of negative loads exists and was available of oxygen atom in clay structure. And also, certain quantities of pores exist in the mineral, which it has possible to join with a smaller percentage of molecules that contains a higher ammonium concentration. The total phosphorous value of a sample was $23.40 \mathrm{ppm}$ and this value considered as high toxic for water to reuse. But after treatment, the value reduced to 3.65 ppm\& reduction percent was $84.40 \%$. This may be due to the fact that nanocomposite bentonite/MIONPs possesses a specific capacity of pores for the adsorption of substances, and when a greater amount of phosphorus is present, not all the phosphorus can be adsorbed in a similar way as previously outlined for ammonium. In phosphorus removal, besides the dependence shown with its own concentration in the medium, a slight dependence with the ammonium concentration was also observed when this concentration was increased in the medium. This may be due to the fact that, because of the attraction of loads that exists among these positive ions, 
ammonium enters the pores of the mineral before the other molecules to the sectors where negative loads generated by oxygen atoms are present. This is all from the point of view of the attraction of loads. However, when analyzing the size of the ions, it should be pointed out that because ammonium ions are smaller than phosphate ions, they enter the pores of the mineral more readily (Magdy et al., 2015).

Table 7: Chemical analysis of polluted wastewater before \& after treatment of nanocomposite bentonite/MIONPs

\begin{tabular}{lcc}
\hline Parameters & TN / ppm & TP /ppm \\
\hline Before treatment & 56.87 & 23.40 \\
After treatment & 10.43 & 3.65 \\
Reduction \% & $81.65 \%$ & $84.40 \%$ \\
\hline Op & &
\end{tabular}

Optimal conditions; Nanocomposite dosage: 8 g/l; Contact time: 30 min.; Temp.: $50{ }^{\circ} \mathrm{C} ; \mathrm{PH}: 7.0$; TN: Total Nitrogen; TP: Total Phosphorus

\subsection{Chemical treatment of COD, BOD \& TOC of wastewater sample by nanocomposite bentonite/MIONPs}

COD (Chemical Oxygen Demand) was the most popular alternative test to BOD for establishing the concentration of organic matter in wastewater samples. The amount of oxygen required (COD or BOD) may change while the carbon concentration (reflected by the TOC value) does not. Table 8 showed that COD value before treatment was $546.07 \mathrm{ppm}$ and after treatment by nanocomposite bentonite/MIONPs was $105.14 \mathrm{ppm}$ and reduction \% value was $80.74 \%$. BOD (Biochemical Oxygen Demand) is a traditional, most effective for testing to establish concentration of organic matter in wastewater samples (i.e., relative strength). BOD value before treatment was $496.32 \mathrm{ppm}$ and after treatment was $79.50 \mathrm{ppm}$ and reduction \% value was $83.98 \%$ (Wu et al., 2002).

Table 8: Reduction percent of COD/BOD/TOC in wastewater before \& after treatment

\begin{tabular}{lccc}
\hline Parameters & COD (ppm) & BOD5 (ppm) & TOC(ppm) \\
\hline Before Treatment & 546.07 & 496.32 & 425.80 \\
After Treatment & 105.14 & 79.50 & 75.14 \\
Reduction \% & 80.74 & 83.98 & 82.35 \\
\hline Orduc & & &
\end{tabular}

Optimal conditions; Nanocomposite dosage: $8 \mathrm{~g} / \mathrm{l}$; Contact time: 30 min.; Temp. : $50{ }^{\circ} \mathrm{C}$; PH: 7.0; COD: chemical oxygen demand BOD: Biochemical oxygen demand TOC: Total organic compounds

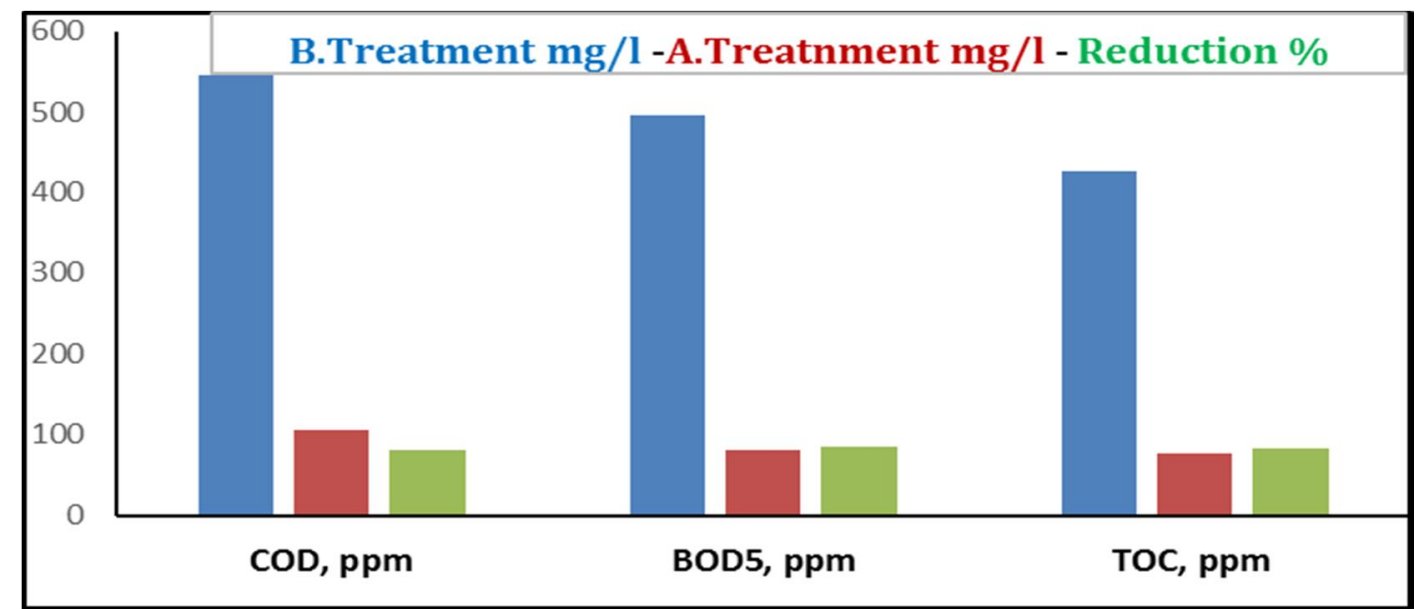

Fig. 11: Chemical Analysis of polluted wastewater before \& after treatment of nanocomposite bentonite/MIONPs

\subsection{Evaluation the relations ratios between COD/BOD and TOC}

Extensive observation of the COD and BOD levels on the same wastewater has shown that the COD to BOD ratio of wastewater will stay constant over time. The mean average value of COD/BOD ratio was 1.10 before treatment. The more variable the ratio values, as in, the higher the COD/BOD ratio, the greater the percent of slow biodegradation and non-biodegradable materials. $\mathrm{BOD}_{5}$ test gave a lower value than is the oxygen demand in the sample (Sivakumar et al., 2015). The ratio value of 
$\mathrm{COD} / \mathrm{TOC}$ was 1.28 before and 1.39 after treatment. The ratio value of $\mathrm{TOC} / \mathrm{BOD}_{5}$ was 0.86 before treatment and 0.94 after treatment. Table 5 showed that after treatment by nanocomposite bentonite/MIONPs increase in ratio value. After treatment with nanocomposite bentonite/MIONPs, the effluent or floating liquid of this process increased the value to 1.34. This result can be attributed to a higher removal of $\mathrm{COD}$ than of $\mathrm{BOD}_{5}$ probably due to the fact that before the application of nanocomposite bentonite/MIONPs removal, some compounds may had hindered the process of biological degradation developed during the BOD5 test but that were adsorbed by the nanocomposite bentonite/MIONPs.

Table 9: Chemical analysis of polluted wastewater before \& after treatment of nanocomposite bentonite/MIONPs

\begin{tabular}{cccc}
\hline Parameters & COD/BOD 5 ratio & COD/TOC ratio & TOC/BOD5 ratio \\
\hline Before Treatment & 1.10 & 1.28 & 0.86 \\
After Treatment & 1.32 & 1.39 & 0.94 \\
\hline
\end{tabular}

Optimal conditions; Nanocomposite dosage: $8 \mathrm{~g} / 1$; Contact time: 30 min.; Temp.: $50{ }^{\circ} \mathrm{C} ;$ PH: 7.0 ; TSS: Total suspended solids; COD: chemical oxygen demand; BOD: Biochemical oxygen demand

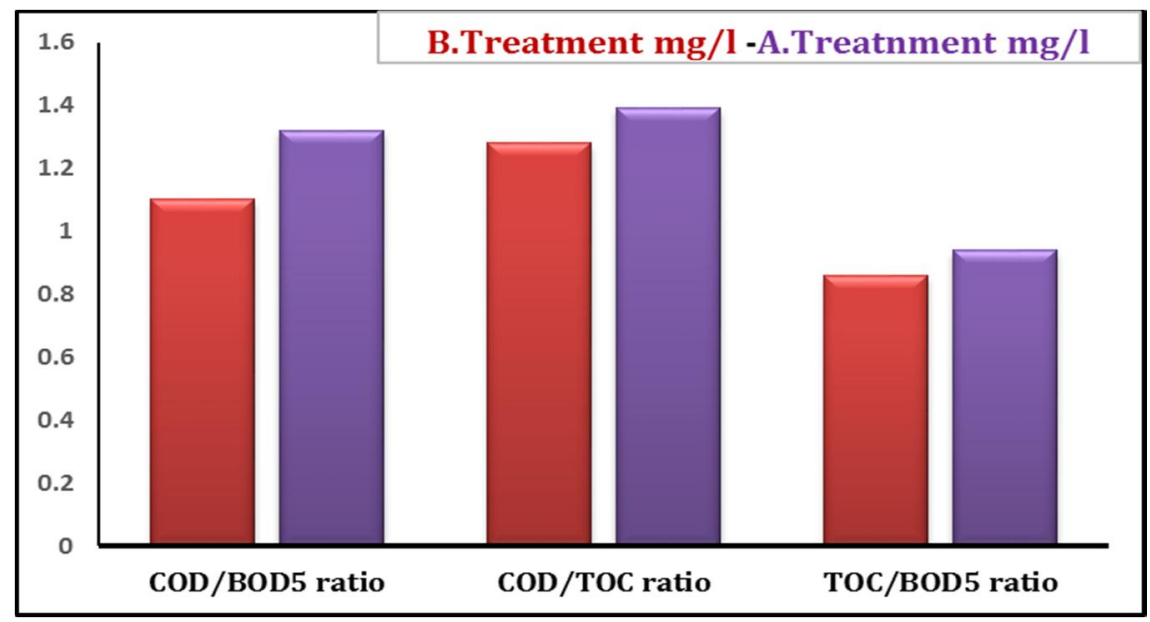

Fig. 12: Chemical analysis of polluted wastewater before $\&$ after treatment of nanocomposite bentonite/MIONPs

\subsection{Adsorption properties of magnetite nanoparticles for $\mathrm{Fe}$ and $\mathrm{Mn}$ removal}

Adsorption isotherm models are fundamental for describing the interactive behavior between the adsorbate and adsorbent. In this study, equilibrium data were analyzed using the Freundlich and Langmuir isotherms. The equilibrium adsorption isotherms and the Freundlich and Langmuir isotherm linearized models. Replicates of the adsorption experiments were run in order to evaluate the experimental reproducibility. The experiments were performed in triplicate and the mean values were considered for the Langmuir isotherm. The standard deviation (SD) for each point of the Langmuir isotherm of the replicates of the uptake of iron and manganese onto commercial and synthetic magnetic nanoparticles. The Langmuir model is based on the assumption of monolayer adsorption on a structurally homogeneous adsorbent, where all sorption sites are identical and energetically equivalent (Suzuki, 1990). The linear form of the Langmuir equation can be expressed according Eq.

$$
C_{e} / q_{e}=C_{e} / q_{m}+1 /\left(K_{L} \times q_{\mathrm{m}}\right)
$$

Where $\mathrm{q}_{\mathrm{m}}$ is the theoretical maximum adsorption capacity corresponding to monolayer coverage $(\mathrm{mg} / \mathrm{g})$, and $\mathrm{k}_{\mathrm{L}}$ is the Langmuir constant $(\mathrm{L} / \mathrm{mg})$. The $\mathrm{k}_{\mathrm{L}}$ and $\mathrm{q}_{\mathrm{m}}$ were determined from the linear and angular coefficients of the equations formed by regressing $\mathrm{Ce} / \mathrm{qe}$ as a function of $\mathrm{C}_{\mathrm{e}}$. The empirical Freundlich equation is applicable to adsorption on heterogeneous surfaces, where the interaction between the adsorbed molecules is not limited to the formation of a monolayer. The Freundlich constant $\left(\mathrm{k}_{\mathrm{F}}\right)$ is related to the adsorption capacity of the adsorbent: the higher the value, the greater the affinity for the adsorbate. The empirical parameter $1 / \mathrm{n}$ is related to the strength of adsorption, which varies with 
the heterogeneity of the material. When the values of $1 / \mathrm{n}$ are between 0.1 and 1.0 , the adsorption process is considered favorable (Liu et al., 2011). The linearized form of the Freundlich equation is expressed according Eq.

$$
\ln q_{e}=\ln K_{F}+1 / n \ln C_{e}
$$

Where $\mathrm{k}_{\mathrm{F}}$ is the Freundlich constant $(\mathrm{L} / \mathrm{g})$ and $1 / \mathrm{n}$ is a dimensionless empirical parameter. The $\mathrm{k}_{\mathrm{F}}$ and $1 / \mathrm{n}$ values were determined from the linear and angular coefficients of the equations formed by regressing $\ln$ qe as a function of $\ln \mathrm{Ce}$, respectively. To determine whether the adsorption process is favorable, a dimensionless constant separation factor $\mathrm{R}_{\mathrm{L}}$ was defined. The adsorption process is irreversible when $\mathrm{R}_{\mathrm{L}}$ is zero, favorable 17 when $\mathrm{R}_{\mathrm{L}}$ is between zero and 1.0 , linear when $\mathrm{R}_{\mathrm{L}}$ is equal to 1.0, and unfavorable when $\mathrm{R}_{\mathrm{L}}$ is greater than 1.0. The $\mathrm{R}_{\mathrm{L}}$ parameter can be defined as:

$$
R_{L}=\mathbf{1} / \mathbf{1}+K_{L} C_{0}
$$

Where $\mathrm{C}_{0}$ is the initial metal ion concentration $(\mathrm{mg} / \mathrm{L})$. The results obtained in our study regarding the adsorption capacity of $\mathrm{Fe}$ and $\mathrm{Mn}$ on nanocomposite samples are in good agreement with other similar studies (Mehdinia et al., 2015). The comparative results showed that the removal efficiencies of the investigated adsorbents were comparable or higher, in some cases. Our results are in good agreement with our results and were given as possible explanation for the complexation capability (donor-acceptor interaction) between the surface of the adsorbent and the metal ions.

Table 10: Parameters derived from both Langmuir and Freundlich fitting models for iron and manganese adsorption on synthetized nanocomposite.

\begin{tabular}{lccccccc}
\hline & \multicolumn{3}{c}{ Langmuir Isotherm } & \multicolumn{3}{c}{ Freundlich Isotherm } \\
\hline & $\mathbf{q} \mathbf{m}(\mathbf{m g} / \mathbf{g})$ & $\mathbf{K}_{\mathbf{L}}$ & $\mathbf{R}_{\mathbf{L}}$ & $\mathbf{R}^{\mathbf{2}}$ & $\mathbf{1} / \mathbf{n}$ & $\mathbf{K}_{\mathbf{f}}$ & $\mathbf{R 2}$ \\
\hline Manganese & 72.046 & 0.022 & 0.1239 & 0.998 & 1.145 & 0.737 & 0.971 \\
Iron & 206.611 & 0.029 & 2.491 & 0.997 & 0.824 & 0.076 & 0.9775 \\
\hline
\end{tabular}

qe $\left(\mathrm{mg} \mathrm{g}^{-1}\right)$ is the adsorbed quantity of $\mathrm{Fe}$ and $\mathrm{Mn}$ ions at equilibrium per unit mass of magnetic nanocomposite, $\mathrm{Ce}$ $\left(\mathrm{mg} \mathrm{L}^{-1}\right)$ is equilibrium concentration, $\mathrm{q}_{\max }\left(\mathrm{mg} \mathrm{g}^{-1}\right)$ is the theoretical adsorption capacity, $\mathrm{K}_{\mathrm{L}}$ is Langmuir constant, $\mathrm{K}_{\mathrm{F}}$ and $\mathrm{n}$ are Freundlich constants.

Table 11: Adsorption capacities of Fe/Mn ions obtained by different adsorbents.

\begin{tabular}{lcl}
\hline \multicolumn{1}{c}{ Adsorbent } & $\begin{array}{c}\text { Adsorption capacity } \\
(\mathbf{m g} / \mathbf{g})\end{array}$ & \multicolumn{1}{c}{ References } \\
\hline magnetic bentonite (M-B) Fe3O4 & 26.18 & (Chenglong et al.,2018) \\
Raw Bentonite & 63.7 & (Danková et al., 2017) \\
Magnetic Bentonite & 76.9 & (Danková et al., 2017) \\
hydroxyapatite-sodium alginate & 142.85 & (Erfan et al., 2018) \\
hydroxyapatite-sodium & 77.51 & (Erfan et al., 2018) \\
Magnetic Iron/Bentonite Nanoparticles & 6.33 & (Hao et al., 2009) \\
Nanocomposite of Bentonite Coated Iron & 206.16 & Present work \\
Oxide Nanoparticles (Bentonite/MIONPs) & & \\
\hline
\end{tabular}

The observed adsorption capacity of Bentonite/MIONPs adsorbent toward Fe/Mn ions is acceptable when compared to that obtained by different adsorbents 

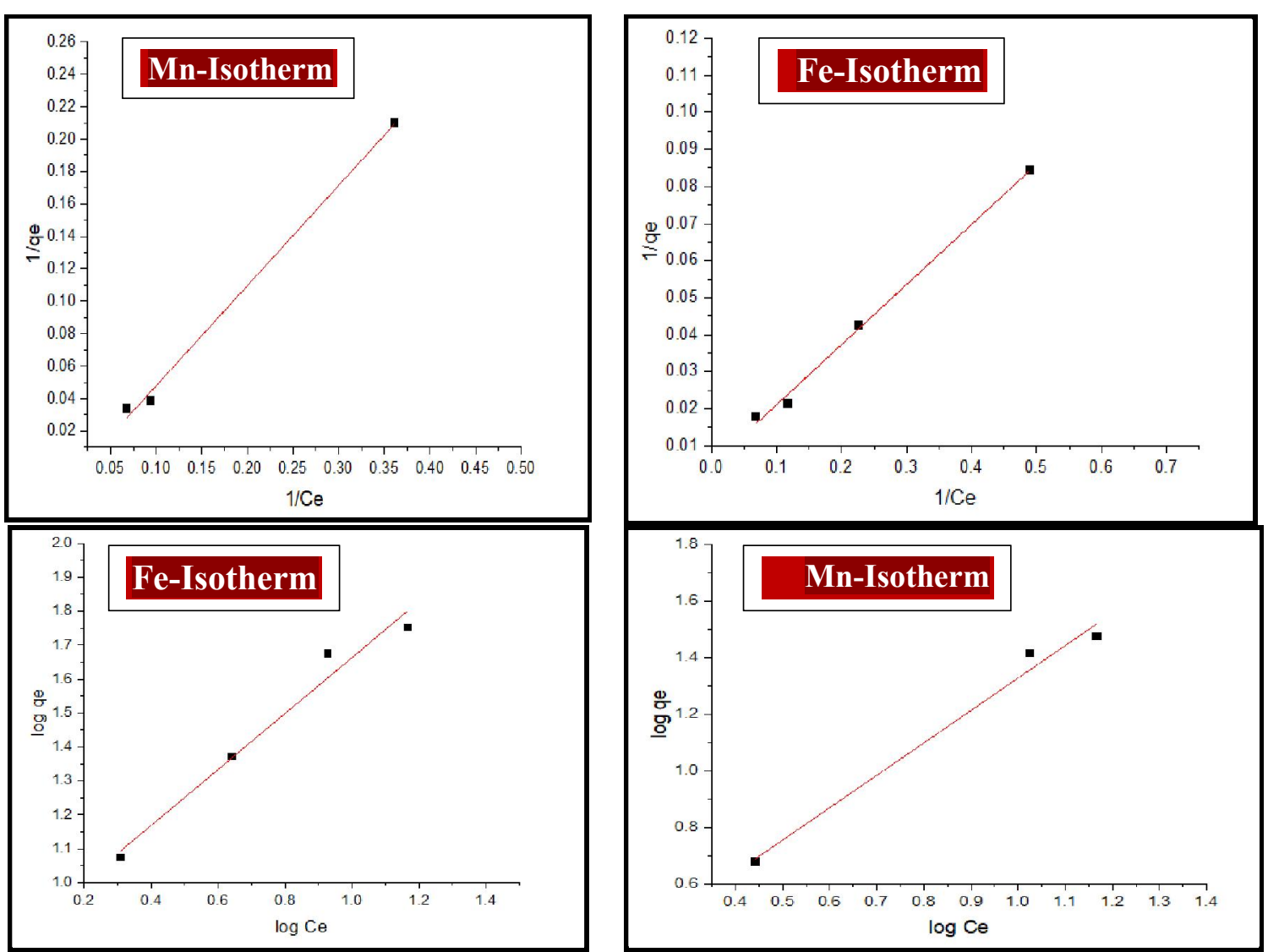

Fig. 13: Langmuir and Freundlich linearized fits for the adsorption of both $\mathrm{Fe}$ and $\mathrm{Mn}$ onto nanocomposite samples

\subsection{Effect of temperature and adsorption thermodynamics.}

Reaction temperature is known to affect adsorption efficiency (Singh et al., 2011). In this research, adsorption experiments were performed at different temperatures and optimal condition of nanocomposite dosage at certain PH. The temperature dependences of $\mathrm{C}_{\mathrm{e}}$ and $\mathrm{q}_{\mathrm{e}}$ are shown in Fig.14. As the temperature increased from 30 to $50{ }^{\circ} \mathrm{C}$, the pollutant removal rate slightly increased. This indicated that the adsorption of pollutant on nanocomposite was favored at high temperature, which suggested that the adsorption process was endothermic. Moreover, thermodynamic analysis revealed the occurrence of chemisorption, the extent of which is known to increase with increasing temperature because of the concomitant facilitation of diffusion (Daou and Amachrouq, 2017). In contrast, the reaction temperature had little effect on the adsorption efficiency, which was in agreement with previously obtained results. The effect of temperature on pollutants adsorption was further studied by thermodynamic analysis using Eqn. (12) - (15) to determine changes in the Gibbs free energy $(\Delta \mathrm{G})$, enthalpy $(\Delta \mathrm{H})$, and entropy $(\Delta \mathrm{S})$ : (Anoop and Anirudhan 2002, Chen et al., 2018).

$\mathrm{K}_{\mathrm{L}}=\mathrm{qe} / \mathrm{Ce}$

$\operatorname{Ln} \mathrm{K}_{\mathrm{L}}=\Delta \mathrm{S} / \mathrm{R}-\Delta \mathrm{H} / \mathrm{RT}$

$\Delta \mathrm{G}=\Delta \mathrm{H}-\mathrm{T} \Delta \mathrm{S}$

$\Delta \mathrm{G}=-\mathrm{RT} \ln \mathrm{K}_{\mathrm{L}}$

Where $\mathrm{K}_{\mathrm{L}}$ is the adsorption distribution constant (L.g-1). $\Delta \mathrm{H}$ and $\Delta \mathrm{S}$ were obtained from the plot of $\ln \mathrm{K}_{\mathrm{L}}$ vs. 1/T (Fig.14) which allows for the determination of $\Delta \mathrm{G}$. Table 12 lists the obtained thermodynamic parameters and the calculated correlation coefficients, and shows that the adsorption $\Delta \mathrm{H}$ was positive. This indicated that the adsorption of pollutants on nanocomposite was endothermic and chemical in nature. The positive value of $\Delta \mathrm{S}$ suggested that adsorption increased randomness at the solid-liquid interface. The $\Delta \mathrm{G}$ values were negative and decreased with increasing temperature, which indicated that adsorption was spontaneous in nature. Furthermore, the increase in $\Delta \mathrm{G}$ with increasing 
temperature suggested that the adsorption of pollutants on nanocomposite was more favorable at higher temperatures. Negative value of Gibb's free energy shows the thermodynamic feasibility and spontaneity of the sorption process. The positive value of $\Delta \mathrm{H}^{\circ}$ confirmed the endothermic nature of iron sorption. Positive value of enthalpy indicated that the increased randomness at the solid solution interface during the fixation of adsorbates on the active sites of the adsorbent. The influence of the nanocomposite particle size on the iron and manganese adsorption capacity revealed that the adsorption capacity for ions increased with the decrease of the nanocomposite particle size. These results were attributed to the increase of the nanocomposite surface area with the decrease of the particle size. Our findings regarding the correlation between the particle size, surface area and arsenic removal efficiency proved to be in agreement with other reported studies. More than that, in agreement with other related studies the higher adsorption capacity for iron and manganese ions obtained for nanocomposite was attributed to the high specific surface area of these nanoparticles (Moussout, et al., 2016).

Table 12: Thermodynamic parameters for metal sorption on the adsorbent

\begin{tabular}{|c|c|c|c|c|c|c|}
\hline \multirow{4}{*}{ Adsorbent } & Temp. (K) & $\mathbf{K}_{\mathbf{L}}$ & $\begin{array}{c}\Delta \mathbf{G}^{0} \\
\left(\text { KJ.mole }^{-1}\right)\end{array}$ & $\begin{array}{c}\Delta \mathbf{H}^{0} \\
\left(\text { KJ.mole }^{-1}\right)\end{array}$ & $\begin{array}{c}\Delta \mathbf{S}^{0} \\
\left(K^{\prime} . m^{\prime}{ }^{-1}\right)\end{array}$ & $\mathbf{R}^{2}$ \\
\hline & 303 & 8.25 & -5.315926702 & \multirow{3}{*}{2.8296} & \multirow{3}{*}{26.8722} & \multirow{3}{*}{0.990} \\
\hline & 313 & 8.517 & -5.574255022 & & & \\
\hline & 323 & 8.845 & -5.853823397 & & & \\
\hline
\end{tabular}

where $\mathrm{K}_{\mathrm{L}}$ is the distribution coefficient, $\mathrm{q}_{\mathrm{e}}\left(\mathrm{mg} \cdot \mathrm{g}^{-1}\right)$ is the uptake capacity at equilibrium and $\mathrm{C}_{\mathrm{e}}\left(\mathrm{mg} \cdot \mathrm{L}^{-1}\right)$ is the equilibrium concentration of the adsorbate and $\Delta \mathrm{G}^{\circ}\left(\mathrm{kJ} \mathrm{mol}^{-1}\right)$ is the change in Gibb's free energy, $\Delta \mathrm{S}^{\circ}\left(\mathrm{J} / \mathrm{mol} \mathrm{K}^{-1}\right)$ is the change in standard entropy, $\Delta \mathrm{H}^{\mathrm{o}}(\mathrm{KJ} / \mathrm{mol})$ is the change in standard enthalpy, $\mathrm{T}(\mathrm{K})$ is the kelvin temperature and $\mathrm{R}$ $\left(8.314 \mathrm{~J} \mathrm{~mol}^{-1} \mathrm{~K}^{-1}\right)$ is the general gas constant.

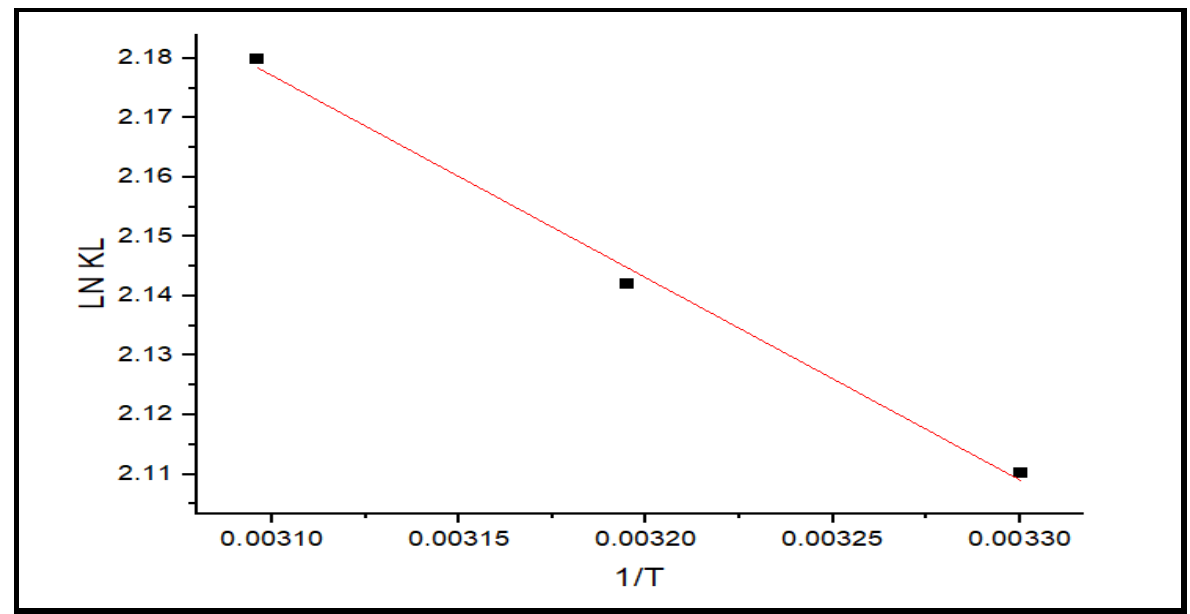

Fig. 14: Thermodynamic for the adsorption of both Fe and Mn onto nanocomposite samples (plot of $\ln$ $\mathrm{K}_{\mathrm{L}}$ versus $1 / \mathrm{T}$ )

\section{Conclusion}

In this paper, the adsorption process was done as a simplest and cheapest method. The big challenge for achievement high removal percent of different pollutants was how to use nanoparticles in wastewater treatment. Addition of bentonite clay mineral to iron oxide nanoparticles by grafting technique was discussed in fig. 1 . The mean average of nanocomposite formed by SEM images showed that the magnetite particles were successfully intercalated into the interior of between bentonite and average diameter of nanoparticles size was $27.50 \mathrm{~nm}$ that help researchers to remove different pollutants such as iron, copper, COD, BOD and TOC with total nitrogen and total phosphorous. Optimal conditions of nanocomposite dosage was $8 \mathrm{~g} / 1$ at contact time 30 min with temperature at $50{ }^{\circ} \mathrm{C}$ and $\mathrm{PH}$ solution 7.0. Bentonite/MIONPs adsorbent considered as an excellent adsorbent at lower $\mathrm{pH}$. The removal efficiency of heavy metals $\mathrm{Fe}$ and $\mathrm{Mn}$ were $89.95 \%$ and $78.82 \%$ respectively. The removal efficiency of total nitrogen and total phosphorous were $84.65 \%$ and $84.40 \%$ respectively. The reduction percent of COD/BOD and TOC were $80.74 \%, 83.98 \%$ and $8.35 \%$. Adsorption data were successfully reproduced by the Langmuir isotherm, and also, $\mathrm{Mn}$ and Fe adsorption saturation capacity was determined as 72.04 and $206.611 \mathrm{mg} . \mathrm{g}^{-1}$ respectively. The average adsorption free energy change 
calculated by adsorption isotherm model was $2.880 \mathrm{~kJ} \mathrm{~mol}^{-1}$, which indicated the occurrence of ionic exchange. Overall, the thermodynamic parameters implied that Mn and Fe adsorption was endothermic and spontaneous. Data derived from kinetics models meant that the adsorption process takes place via strong physical interactions, such as electrostatic attraction, hydrogen bonding and Vander Waal forces, between $\mathrm{Mn}$ and $\mathrm{Fe}$ ions and the adsorbent surface.

\section{Reference}

Abbas, M., M. Takahashi, and C. Kim, 2013. J. Nanopart. Res., 15, 1354.

Ahmad, R.R., R. Adnan, M. Abu Bakar, and M.S. Malik, 2011. J. Phys. Sci. 22 25-37.

Ahmadreza, Y., E. Akbar, Gh. Mostafa, A. Ehsan, M. Mohammad, and A. Bahador, 2015, International Journal of Pharmacy \& Technology, ISSN: 0975-766X Coden: IJPTFI 290451484.

Anoop and T.S. Anirudhan, S.M. Awadh and F.H. Abdulla, 2002. 92: 161-183. 43 J. Hazard, Mater, Environ. Earth Sci. 76, 386. $44 \mathrm{H}$.

Betega de Paiva, L., A.R. Morales, and F.R. Valenzuela Diaz, 2008. Organo clays Properties,Appl. Clay Sci., 42: 8- 24, (). DOI: org/10.1016/j.clay.2008.02.006.

Binh, V.T., S.T. Purcell, and V.F. Semet, 1998. Appl. Surf. Sci. 130-132 803-814.

Bourlinos, A.B., and M.A. Karakassides, 2000. Chem. Mater. 12-2640.

Brazel, C.S., 2009. Pharm. Res. 26: 644-56.

Catalano, E., M. Miola, S. Ferraris, S. Novak, F. Oltolina, A. Cochis, M. Prat, E. Vernè, L. Rimondini, and A. Follenzi, 2017. Biomed. Phys. Eng. Express, 3025015.

Chen, Q.S., B. Huang, S.W. Wang and L.Y. Wang, 2018. J. Radioanal. Nucl. Chem., 316: 71-80. 45H.

Chenglong, Z., L. Jiyan, J. Wei, G. Yinyan and Z. Yichen, 2018Adsorption behavior of magnetic bentonite for removing $\mathrm{Hg}$ (II) from aqueous solutions., DOI: 10.1039/c8ra05247.

Cornell, R.M., and U. Schwertmann, 2003. 2nd Edn. Wiley-VCH Verlagsgesellschaft Weinheim.

Danková, Z., E. Fedorová, A. Bekényiová, Z. Dankanova, et al., 2017. Bentonite/iron., Archives for Technical Sciences 16(1), 65-75. DOI: 10.7251/afts.2017.0916.065D COBISS.RS-ID 6440472.

Daou, O.Z. and A. Amachrouq, 2017. Water Sci. Technol. 75, 1098-1117. 42 K. K.

De Mello, L.B., L.C. Varanda, F.A. Sigoli, and I.O.J. Mazali, 2019. Alloys Compd. 698-705.

Ding, S., Y. Sun, C. Yang, and B. Xu, 2009. 19(4): 489-492.

Duman O. and E. Ayranci, 2006. Sep. Sci. Technol. 41, 3673. DOI: 10.1080/ 01496390600915072.

Elı'as, O., V. MarcosI, , G.E. Urreta, E. Silvia, and S.P.S. Eimer, 2010. Journal of Magnetism and Magnetic Materials, 322: 3438-3442.

Erfan, S., S. Farhad, and J. Alireza, 2018. Removal of Arsenic and Copper from Water Solution Using Magnetic Iron/Bentonite Nanoparticles (Fe3O4/Bentonite). DOI.org/10.1007/s12633-018-9895$\mathrm{z}$.

Freundlich, H., 1906. Phys. Chem., 57, 385.

Guibal, E., C. Milot and J.M. Tobin, 1998. Ind. Eng., Chem. Res., 37: 1454.

Gusain, D., V. Srivastava, and Y.C. Sharma, 2014. J. Ind. Eng. Chem., 20: 841-847.

Habib, N.R., A.M. Taddesse, and A. Temesgen Synthesis, characterization and photocatalytic activity of $\mathrm{Mn} 2 \mathrm{O} 3 / \mathrm{A} 12 \mathrm{O} 3 / \mathrm{Fe} 2 \mathrm{O} 3$ nanocomposite for degradation of malachite green., 2018. Bulletin of the Chemical Society of Ethiopia, 32 (1): 101-109.

Hao, J., M.J. Han, and X. Meng, 2009. Preparation and evaluation of thiol-functionalized activated alumina for arsenite removal from water. J. Hazard Mater.167:1215-21. http://www.ncbi.nlm.nih.gov/ PubMed/19269090.

Hasanpour, M., 2020. Adv. Colloid Interface Sci. 284, 102247. DOI:10.1016/j.cis.2020.102247.

Hashim, M.A., S. Mukhopadhyay, J.N. Sahu and B. Sengupta, 2011. J. Environ. Manage. 92, 2355. DOI:10.1016/j.jenvman.2011.06.009.

He, H., Y. Ma, J. Zhu, P. Yuan, and Y. Qing, 2010. Appl. Clay Sci., 48 (1-2): 67-72.

DOI: org/10.1016/j.clay.2009.11.024.

Helena, L., G. Chaves, and G.A. Tito, 2011. Revista Ciencia Agronomica, 42(2): 278-284. DOI: 10.1590/ S1806-66902011000200004.

Hong, R.Y., S.Z. Zhang, Y.P. Han, H.Z. Li, J. Ding and Y. Zheng, 2006. Powder Technology, 170: 111. 
Indira, T.K., and P.K. Lakshmi, 2010. Magnetic nanoparticles - A review, Int. J. Pharm. Sci. Nanotechnol., 3: 1035-1042.

Jakir, H.Md., M.A. Gafur, M.R. Kadir, and K.M. Mainul, 2014. Int., J. Eng. Technol. 14: 24-32.

Karapinar N., and R. Donat, 2009. Desalination, 249: 123-129.

Karnland, O., S. Olsson, and U. Nilsson, 2006. Mineralogy and sealing properties of various bentonites and smectite-rich clay materials. SKB Stockholm.

Kurlyandskaya, G.V., A.V. Svalov, B.A. Burgoa, F.A. Blyakhman, A.P. Safronov, F.A. Blyakhman, A.V. Svalov, E. Fernández, E. Fernández, A.P. Safronov, and I.V. Beketov, 2017. J. Magn. Magn. Mater., 441 650-5.

Landeloutin, H., 1987. Chemistry of Clays and Clay Minerals (A. C. D. Newman, Eds.), vol. 6. Longman Scientific \& Technical, Harlow, 30. McBride, M. B., Environmental Chemistry of Soils. Oxford Univ. Press.

Li, H., Z. Lu, G. Cheng, K.F. Rong, F.X. Chen, and R. Chen, 2015. RSC Adv., 5: 5059-5067.

Liu, R., B. Zhang, D. Mei, H. Zhang and J. Liu, 2011. Adsorption of methyl violet from aqueous solution by halloysite nanotubes., Desalination, 268: 111-116.

Lu, G., S. Li, Z. Guo, O.K. Farha, B.G. Hauser, X. Qi, Y. Wang, X. Wang, S. Han, X. Liu, J.S. Duchene, H. Zhang, Q. Zhang, and X. Chen, 2012. J. Ma Loo S C J.Wei, D.W Yang, J T. Hupp, F. Huo, Imparting functionality to a metal-organic framework material by controlled nanoparticle encapsulation. Nat. Chem., 4: 310-6.

Magdy, H.E., and A.M.A. Yasser, 2015. Egyptian J. Desert Res., 65(1): 81-99.

Mahdavi, M.F., M.B. Namvar, and M. Ahmad, 2007. Moecules R., 18: 5954-596.

Mehdinia, A., S. Shegefti, and F. Shemirani, 2015. Removal of Lead (II), Copper (II) and Zinc (II) Ions from Aqueous Solutions Using Magnetic Amine-Functionalized Mesoporous Silica Nanocomposites, J. Braz. Chem. Soc., 26: 2249-2257.

Melichova, Z., and L. Hromada, 2012. 22(2): 457-464.

Meng J., X. Feng, Z. Dai, X. Liu, J. Wu and J. Xu, 2014. Environ. Sci. Pollut. Res. 21, 7035. DOI: 10.1007/s11356-014-2627-Z.

Moussout, A.H., M. Aazza, O. Zegaoui and A.C. El, 2016. Water Sci. Technol., 73: 2199-2210.

Murray, H.H., 2006. Applied clay mineralogy: occurrences, processing and applications of kaolins, bentonites, palygorskitesepiolite, and common clays, vol 2.Elsevier, Amsterdam.

Nasser, Sh., E. Radwa, and M.A.E. Ahmed, 2018. New Journal of Chemistry 42(1). DOI: $10.1039 / \mathrm{C} 8 \mathrm{NJ} 01479 \mathrm{E}$

Ooi, F., J.S. DuChene, J.J. Qiu, J.O. Graham, M.H. Engelhard, G.X. Cao, and Z. GaiWei, 2015, Small, 11: 2649-2653.

Petcharoen, K., and A.M. Sirivat 2012. Sci. Eng. B-Adv. 177, 421-427. DOI: org/10.1016/j.mseb.2012.01.003

Rajput M.S., A. Sharma, S. Sharma and S. Varma, 2015. Int. J. Appl. Res. 1, 411.

Roul, J., R. Mohapatra, and S.S. Kumar, 2013. J. Biomed. Pharm. Sci., 3: 33-38.

Safronov, A.P., E.A. Mikhnevich, Z. Lotfollahi, F.A. Blyakhman, T.F. Sklyar, A. Larrañaga, A.I. Varga Medvedev, S. Fernández, and G.V. Armas Kurlyandskaya, 2018. Sensors (Switzerland) 18.

Sangeetha, K., G. Vasugi, and E.K. Girija, 2015. Int., J. Chem. Tech.Res. 8, 117-125.

Sarma, B., A.L. Juroyitzki, Y.R. Smith, R.S. Ray, and M. Misra, 2014. J. Power Sources 272 766-775.

Singh, S., K.C. Barick, and D. Bahadur, 2011. Surface engineered magnetic nanoparticles for removal of toxic metal ions and bacterial pathogens., J. Hazard. Mater., 192: 1539- 1547.

Sivakumar, D., J. Rajaganapathy, R. Anand, S. Mariavensa, and S. Preethi, 2015. Journal of Chemical and Pharmaceutical Sciences. ISSN: 0974/296124718.

Solano, E., L. Perez-Mirabet, F. Martinez-Julian, and R. Guzman, 2012. J. Arbiol, T. Puig, X. Obradors, R.Yanez, A. Pomar, S. Ricart, J. Nanopart. Res. 14, 15.

Strobel, R., S.E. Pratsinis, and J. Mater. 2007. Chem. 17: 4743-4756.

Suzuki, M., 1990. Adsorption Engineering, 4th Edn, Kodansha, Tokyo.

Tamas S., B. Aristides, T. Vassilios, P. Szilvia, K. Laszl ' o, G. Gabor, M. Kuanyshbek, B. Didara, P. Dimitris and D. Imre, 2007. Nanotechnology 18285602 (9pp). DOI: 10.1088/0957 $4484 / 18 / 28 / 285602$.

Tsukasa, T., 2017, Electrochemistry, 85 (9): 534 542. DOI: org/10.5796/electrochemistry.85.534. 
Upadhyay U., I. Sreedhar, S.A. Singh, C.M. Patel and K.L. Anitha, 2021. Carbohydr. Polym. 251, 117000. DOI:10.1016/j.carbpol.2020.117000.

Varanda, L.C., M.Jr. Jafelicci, P. Tartaj, K.O. Grady, T. Gonzalez-Carreno, M.P.T. Morales, and C.J. Munoz, , 2002. J. Appl. Phys., 92: 2079-2085.

Vasugi, G., and E.K. Girija, 2015. Chem. Technol., 49 87-91.

Wang J.H., M.X. Gao, D.S. Wang, X. Li, Y.B. Dou, Y.F. Liu, and H.G. Pan, 2015. Power Sources, 282 : 257-264.

Wisotzki, E.I., D. Eberbeck, H. Kratz, and S.G. Mayr, 2016. Soft Matter, 12: 3908-18.

World Health Organization, 2004. Manganese and its Compounds: Environmental Aspects: Concise International Chemical Assessment Document, World Health Organization, Geneva, Switzerland,

Wu, X.L., Y.T. Guan, X. Zhang, X. Huang, and Y. Qian, 2002. Environ. Technol. 23: 677-684.

Younes A.A., M.H. Taha and A. Masoud, 2018. Sep. Sci. Technol. 53, 2573. DOI: 10.1080/ 01496395.2018.1467450.

Zhu, F., Y. Zheng, B. Zhang and Y.J. Dai 2021. Hazard. Mater. 401, 123608. DOI: 10.1016/j. jhazmat.2020.123608.

Zuzana, M., and H. Michaela, 2015. Solid State Phenomena, 244, 205-212. Doi: 10.4028/www.scientific. net/SSP.244.205. 